\begin{tabular}{|c|c|}
\hline Title & $\begin{array}{l}\text { Insights into Geometries, Stabilities, Electronic Structures, Reactivity Descriptors, and Magnetic Properties of } \\
\text { Bimetallic NimCun-m }(m=1,2 ; n=3-13) \text { Clusters: Comparison with Pure Copper Clusters }\end{array}$ \\
\hline Author(s) & Singh, Raman K.; Iwasa, T akeshi; T aketsugu, Tetsuya \\
\hline Citation & $\begin{array}{l}\text { Journal of computational chemistry, 39(23), 1878-1889 } \\
\text { https://doi.org/10.1002/ Jcc.25361 }\end{array}$ \\
\hline Issue Date & $2018-09-05$ \\
\hline Doc URL & http:/hdl.handle.net/2115/75435 \\
\hline Rights & $\begin{array}{l}\text { This is the peer reviewed version of the following article: Journal of Computational Chemistry, V olume39, Issue23, } \\
\text { September } 5,2018 \text {, Pages } 1878-1889, \text { which has been published in final form at https://doi .org/10.1002 Jcc. } 25361 \text {. This } \\
\text { article may be used for non-commercial purposes in accordance with Wiley Terms and Conditions for U se of Self- } \\
\text { A rchived V ersions. }\end{array}$ \\
\hline Type & article (author version) \\
\hline File Information & NiCu-JCC-hokudai .pdf \\
\hline
\end{tabular}

Instructions for use 
Insights into Geometries, Stabilities, Electronic Structures, Reactivity Descriptors, and Magnetic Properties of Bimetallic $\mathrm{Ni}_{m} \mathrm{Cu}_{n-m}(m=1,2 ; n=3-13)$ Clusters: Comparison with Pure

\title{
Copper Clusters
}

\author{
Raman K. Singh ${ }^{[\mathrm{a}, \mathrm{b}]}$ Takeshi Iwasa, ${ }^{[\mathrm{a}, \mathrm{c}]}$ and Tetsuya Taketsugu ${ }^{*[\mathrm{a}, \mathrm{c}]}$
}

[a] Raman K. Singh, Takeshi Iwasa, Tetsuya Taketsugu

Elements Strategy Initiative for Catalysts and Batteries (ESICB), Kyoto University, Kyoto 615-8245, Japan

[b] Raman K. Singh

Department of Chemistry, Jagdam College, Chapra Jai Prakash University, Chapra, Bihar - 841301, India

[c] Takeshi Iwasa, Tetsuya Taketsugu

Department of Chemistry, Faculty of Science, Hokkaido University, Sapporo 060-0810, Japan

Corresponding author (Tetsuya Taketsugu)

E-mail:take@sci.hokudai.ac.jp 


\section{ABSTRACT:}

A long-range corrected density functional theory (LC-DFT) was applied to study the geometric structures, relative stabilities, electronic structures, reactivity descriptors and magnetic properties of the bimetallic $\mathrm{NiCu}_{n-1}$ and $\mathrm{Ni}_{2} \mathrm{Cu}_{n-2}(n=3-13)$ clusters, obtained by doping one or two $\mathrm{Ni}$ atoms to the lowest energy structures of $\mathrm{Cu}_{n}$, followed by geometry optimizations. The optimized geometries revealed that the lowest energy structures of the $\mathrm{NiCu}_{n-1}$ and $\mathrm{Ni}_{2} \mathrm{Cu}_{n}$ 2 clusters favor the Ni atom(s) situated at the most highly coordinated position of the host copper clusters. The averaged binding energy, the fragmentation energies and the second-order energy differences signified that the $\mathrm{Ni}$ doped clusters can continue to gain an energy during the growth process. The electronic structures revealed that the highest occupied molecular orbital (HOMO) and the lowest unoccupied molecular orbital (LUMO) energies of the LCDFT are reliable and can be used to predict the vertical ionization potential and the vertical electron affinity of the systems. The reactivity descriptors such as the chemical potential, chemical hardness and electrophilic power, and the reactivity principle such as the minimum polarizability principle are operative for characterizing and rationalizing the electronic structures of these clusters. Moreover, doping of Ni atoms into the copper clusters carry most of the total spin magnetic moment. 


\section{Introduction}

During the last few decades, transition-metal clusters have attracted much attention because of their physical and chemical properties that are different from those of bulk metals. The typical advantage of the clusters involves catalytic activities, stability and easy recovery. Since the clusters have the large surface-to-volume ratio leading to the unique geometries, electronic and magnetic properties, a detailed study of the evolution of the structural, relative stabilities, electronic and magnetic properties of the clusters is always indispensable to bridge our understanding over atoms, nanoparticles and the bulk. ${ }^{1,2}$

Nowadays there is a growing demand on nonprecious-metal catalysts due to a limited amount of precious metals, and the catalytic activity of copper nanoclusters has emerged as one of the promising candidates in various areas of sensing, ${ }^{3,4}$ biolabeling, ${ }^{5}$ and catalysis. ${ }^{6-14}$ This is apparent reason that copper clusters are currently the hot topics in research. However, the controlled synthesis, stabilization and characterization of small clusters is a cumbersome task, ${ }^{15,16}$ and quantum chemical studies provide the geometric, electronic, and chemical properties to understand the origin of the exceptional catalytic activity. To this end, the reactivity of copper clusters, and its evaluation with the number of atoms in the cluster, has been investigated theoretically ${ }^{17-26}$ but much more need still to be done to design a better catalyst.

In 1960s, the concept of bimetal was proposed, and since then bimetallic alloys have been receiving much interests due to their wide range of applications in heterogeneous catalysis. The addition of a second metal to the host metal surface can sometimes dramatically improve the selectivity, activity, and stability in surface-catalyzed reactions. ${ }^{15,16}$ Similarly, in cluster chemistry, cluster size, shape, composition and oxidation state are important parameters responsible for affecting the metal cluster properties. ${ }^{27-31}$ These properties may dramatically change when doped with another metal atom. The previous studies have shown that bimetallic 
nanoalloys are better catalyst than pure metals and they are in demand in various commercial electrocatalytic and catalytic processes. ${ }^{32,33}$ Therefore, researchers envisioned that copper clusters doped with different transition-metal atoms will be a new kind of molecular architecture to provide the desired structural, electronic, magnetic, optical and catalytic properties for potential applications in nanotechnology, materials science, microelectronics, biology, medicine and solid-state chemistry. ${ }^{3-16,34}$

Recently, Ni-doped copper alloys have been investigated to exploit their untapped potential for better catalytic performance. For instance, Nerlov et al. ${ }^{35-37}$ reported that the $\mathrm{Cu}-$ $\mathrm{Ni}$ catalysts are 60 times more active for $\mathrm{CO}_{2}$ activation compared with the pure copper, while Liu et al. ${ }^{38}$ found that $\mathrm{Pd}, \mathrm{Rh}, \mathrm{Pt}$, and Ni metals are able to promote the methanol production on $\mathrm{Cu}(111)$. Yang et al. ${ }^{39}$ noted that the $\mathrm{Cu}_{29}$ nanoparticles with or without $\mathrm{ZnO}$ support exhibit a higher catalytic activity than $\mathrm{Cu}(111)$ for the methanol synthesis via $\mathrm{CO}_{2}$ hydrogenation. It indicates that doping of $\mathrm{Ni}$ atoms into $\mathrm{Cu}$ clusters would be more promising for the catalytic hydrogenation of $\mathrm{CO}_{2}$ into methanol than the pure copper ones. Moreover, Cheng and his coworkers ${ }^{39}$ theoretically studied the role of composition and geometric relaxation in $\mathrm{CO}_{2}$ binding to the $\mathrm{Cu}-\mathrm{Ni}\left(\mathrm{Cu}_{54} \mathrm{Ni}, \mathrm{Cu}_{42} \mathrm{Ni} 13\right)$ bimetallic clusters. It was concluded that icosahedral $\mathrm{Cu}_{42} \mathrm{Ni}_{13}$ cluster exhibits the strongest $\mathrm{CO}_{2}$ adsorption ability with respect to $\mathrm{Cu}_{55}$ and $\mathrm{Cu}_{54} \mathrm{Ni}$ clusters. On the other hand, Austin et al. ${ }^{40}$ demonstrated that doping of $\mathrm{Ni}$ on the surface of $\mathrm{CuNi}$ $\left(\mathrm{Cu}_{43} \mathrm{Ni}_{12}, \mathrm{Cu}_{12} \mathrm{Ni}_{43}, \mathrm{Cu}_{42} \mathrm{Ni}_{13}, \mathrm{Cu}_{13} \mathrm{Ni}_{42}\right)$ bimetallic nanoparticles can significantly enhance the $\mathrm{CO}_{2}$ adsorption. Derosa et al. ${ }^{41}$ computationally studied a planar configuration of $\mathrm{Cu}-\mathrm{Ni}$ clusters containing up to five atoms and concluded that $\mathrm{Cu}$ clusters with small concentration of $\mathrm{Ni}$ could be the best adsorbents for hydrogens. However, Han et al. ${ }^{42}$ performed the spinpolarized density functional theory (DFT) calculations using the Projector augmented-wave (PAW) method ${ }^{43,44}$ and Perdew-Burke-Ernzerhof (PBE) functional ${ }^{45}$ to study the chemical activities of $\mathrm{Cu}_{n} \mathrm{Ni}$ clusters $(n=1-12)$ toward the $\mathrm{CO}_{2}$ adsorption. Since the PAW method was 
conceived for solids, its accuracy to deal with molecular systems might be less than that of both DFT and a wave function theory using atom-centered basis functions, and their results may not be directly comparable. In light of above mentioned work, a systematic, in-depth study of the structural evolution and properties of Ni-doped copper clusters are still lacking. This study is, therefore, urgently warranted for designing cheaper and more efficient $\mathrm{Ni}-\mathrm{Cu}$ catalyst.

Currently, the generalized Kohn-sham (KS) method $^{46}$ using the long-range corrected ${ }^{47}$ (LC-) DFT has solved many deep-seated problems in conventional DFT methods such as a poor description of van der Waals bonds,${ }^{48}$ an underestimation in excitation energies by timedependent (TD) DFT, ${ }^{49,50}$ poor evaluations of hyperpolarizabilities ${ }^{51}$ and valence orbitals energies. ${ }^{52-54}$ Despite its huge potential, LC-DFT has not been extensively used for metalcluster catalysis, to the best of our knowledge. This prompted us to employ such a state-of-theart DFT functional for both quantitative and qualitative calculations. Therefore, in this work, our purpose is to study Ni-doping effects on geometric, relative stabilities, electronic structures, reactivity descriptors, and magnetic properties for the most stable structure of small copper clusters, $\mathrm{Cu}_{n}(n=3-13)$, using the long-range corrected DFT. For comparison, the most stable structure of pure copper clusters, $\mathrm{Cu}_{n}(n=3-13)$, are also systematically studied so that this work could provide practical guidelines for experimental researches in near future.

The paper is organized as follows: in next section 2, a brief description of computational methods is provided. Section 3 is devoted to the results and discussion and in Section 4, we draw our conclusions. 


\section{Computational Details}

The LC-DFT method, LC-BLYP, ${ }^{47,55}$ was employed in conjunction with LANL2DZ basis sets, ${ }^{56}$ for computations of all clusters of $\mathrm{Ni}_{m} \mathrm{Cu}_{n-m}(m=0-2 ; n=3-13)$. The range separation parameter for the LC-BLYP was set 0.47 , which is the optimum value for the ground state calculation. To test the reliability of LC-BLYP, vertical ionization potentials (VIPs), vertical electron affinities (VEAs), bond lengths $\left(R_{\mathrm{e}}\right)$, vibrational frequency $\left(\omega_{\mathrm{e}}\right)$ and binding energies $\left(D_{0}\right)$ of dimers $\left(\mathrm{Cu}_{2}, \mathrm{CuNi}\right.$ and $\left.\mathrm{N}_{2}\right)$ were calculated using LC-BLYP, ${ }^{55} \mathrm{~B} 3 \mathrm{LYP},{ }^{57,58}$ BLYP ${ }^{57,59}$ B3PW91, ${ }^{58,60}$ M06L, ${ }^{61}$ M062X, ${ }^{63}$ BHandHLYP, ${ }^{62}$ PBEPBE, ${ }^{45}$ PBEh1PBE, ${ }^{63}$ PW91P86 $6^{64}$ and PW91PW91 ${ }^{65}$ methods with LANL2DZ basis sets. VIPs and VEAs were estimated from the highest occupied molecular orbital (HOMO) and the lowest unoccupied molecular orbital (LUMO) energies ( $\varepsilon_{\mathrm{HOMO}}$ and $\left.\varepsilon \mathrm{LUMO}\right)$, as well as the energy difference of the neutral $\left(E_{\mathrm{N}}\right)$, cationic $\left(E_{\mathrm{C}}\right)$ and anionic states $\left(E_{\mathrm{A}}\right)$. An SCF=XQC option was used to converge self-consistent-field (SCF) calculations. The most stable copper clusters, $\mathrm{Cu}_{n}(n=3-13)$, were obtained by geometry optimization for the reported most stable structures ${ }^{20}$ with several possible spin multiplicities at the level of LC-BLYP/LANL2DZ. To search the lowest energy structures of the Ni-doped cluster $\mathrm{Ni}_{m} \mathrm{Cu}_{n-m}(m=1,2 ; n=3-13)$, initial geometries were generated by substituting one or two $\mathrm{Cu}$ atoms in the most stable copper clusters with $\mathrm{Ni}$ (the number of geometries is a combination, ${ }_{n} \mathrm{C}_{m}$, for $\mathrm{Ni}_{m} \mathrm{Cu}_{n-m}$ ), and geometry optimization was performed for all possible isomers with several possible spin states at the same level. Harmonic vibrational frequencies were computed to verify that the optimized structures have no imaginary frequency. All computations were performed using the Gaussian 16 package. ${ }^{62}$ 


\section{Results and Discussion}

\section{Geometric Structures}

Table 1 shows VIPs, VEAs, bond lengths, vibrational frequency and binding energies of $\mathrm{Cu}_{2}, \mathrm{CuNi}$ and $\mathrm{Ni}$, calculated by several methods. It is clearly shown that the LC-BLYP results are in best agreement with the experimental values, ${ }^{66,67}$ indicating that LC-BLYP is the best choice for the current molecular systems. The spin multiplicity of the ground states of $\mathrm{Cu}_{2}$, $\mathrm{CuNi}$, and $\mathrm{Ni}_{2}$ are verified to be singlet, doublet, and triplet, respectively. The relative energies of the dimers at different spin states are given in Figure S1 (in supporting information). The calculated bond lengths of these dimers are in good agreement with the corresponding experimental values. ${ }^{66,67}$ The $\mathrm{Ni}-\mathrm{Ni}$ bond length in $\mathrm{Ni}_{2}$ is shorter than the $\mathrm{Cu}-\mathrm{Cu}$ in $\mathrm{Cu}_{2}$ in the experiment, but the LC-BLYP result of Ni-Ni bond length is $0.02 \AA$ longer than the $\mathrm{Cu}-\mathrm{Cu}$ in $\mathrm{Cu}_{2}$. This bond-length discrepancy is also reported in pervious theoretical studies, ${ }^{41,66}$ which may be attributed to the presence of a lot of electronic states lying very close to the ground state. The $\mathrm{Cu}-\mathrm{Cu}$ and $\mathrm{Cu}-\mathrm{Ni}$ bond length differ with the corresponding experimental results by $0.00 \AA$ and $0.02 \AA$, respectively, while the Ni-Ni distance is underestimated by $0.04 \AA$.

As far as the bond dissociation energies of $\mathrm{Ni}_{2}$ dimer are concerned, M062X and BHandHLYP results show negative values. This simply implies that density functionals containing greater than or equal to $50 \% \mathrm{HF}$ exchange predict wrong bond dissociation energies. It warrants the use of such DFT methods and an optimum balance of HF exchange in the DFT functional are essential for the study of the metal clusters. 
Table 1. The VIPs, VEAs, equilibrium bond lengths, vibrational frequencies, and binding energies of $\mathrm{Cu}_{2}, \mathrm{CuNi}$ and $\mathrm{Ni}_{2}$ dimers, calculated by several functionals. The experimental values are also given.

\begin{tabular}{|c|c|c|c|c|c|c|c|}
\hline \multicolumn{8}{|c|}{ Cu-Cu Dimer } \\
\hline \multirow{2}{*}{ Functional } & \multicolumn{2}{|c|}{ VIP (eV) } & \multicolumn{2}{|c|}{ VEA (eV) } & \multirow{2}{*}{$\begin{array}{c}R_{\mathrm{e}} \\
(\AA)\end{array}$} & \multirow{2}{*}{$\begin{array}{c}\omega_{\mathrm{e}} \\
\left(\mathrm{cm}^{-1}\right)\end{array}$} & \multirow{2}{*}{$\begin{array}{c}D_{0} \\
(\mathrm{eV})\end{array}$} \\
\hline & $-\varepsilon_{\text {НОМо }}$ & $E_{\mathrm{C}}-E_{\mathrm{N}}$ & $-\varepsilon_{\text {LUMO }}$ & $E_{\mathrm{N}}-E_{\mathrm{A}}$ & & & \\
\hline LC-BLYP & 7.66 & 7.6 & 0.42 & 0.45 & 2.22 & 282 & 1.87 \\
\hline BLYP & 4.47 & 8.02 & 2.85 & 0.63 & 2.25 & 262 & 2.23 \\
\hline B3LYP & 5.58 & 7.98 & 2.34 & 0.65 & 2.26 & 256 & 1.97 \\
\hline B3PW91 & 5.49 & 7.79 & 2.12 & 0.61 & 2.26 & 260 & 1.88 \\
\hline M06L & 4.19 & 7.7 & 2.09 & 0.37 & 2.22 & 275 & 2.56 \\
\hline M062X & 6.09 & 7.54 & 1.53 & 0.58 & 2.36 & 216 & 1.82 \\
\hline BHandHLYP & 6.06 & 7.45 & 1.37 & 0.4 & 2.29 & 243 & 1.61 \\
\hline PBEPBE & 4.48 & 7.98 & 2.79 & 0.69 & 2.25 & 267 & 2.27 \\
\hline PBEh1PBE & 5.61 & 7.72 & 2 & 0.58 & 2.26 & 260 & 1.88 \\
\hline PW91P86 & 4.72 & 8.26 & 3.04 & 0.87 & 2.23 & 273 & 2.45 \\
\hline PW91PW91 & 4.57 & 8.07 & 2.86 & 0.72 & 2.24 & 269 & 2.3 \\
\hline Experiment $^{\mathrm{a})}$ & \multicolumn{2}{|c|}{7.9} & & & 2.22 & 264 & $2.01 \pm 0.08$ \\
\hline \multicolumn{8}{|c|}{ Cu-Ni Dimer } \\
\hline LC-BLYP & 7.61 & 7.38 & 0.46 & 0.5 & 2.25 & 276 & 1.72 \\
\hline BLYP & 4.41 & 7.65 & 2.91 & 0.69 & 2.26 & 270 & 2.16 \\
\hline B3LYP & 5.55 & 7.5 & 2.35 & 0.67 & 2.29 & 249 & 1.83 \\
\hline B3PW91 & 5.5 & 7.49 & 2.16 & 0.64 & 2.26 & 270 & 1.87 \\
\hline M06L & 4.19 & 7.57 & 2.24 & 0.56 & 2.24 & 284 & 2.31 \\
\hline M062X & 6 & 7.47 & 1.54 & 0.62 & 2.41 & 217 & 1.7 \\
\hline BHandHLYP & 6 & 7.38 & 1.41 & 0.45 & 2.34 & 233 & 1.48 \\
\hline PBEPBE & 4.41 & 7.66 & 2.85 & 0.75 & 2.25 & 276 & 2.25 \\
\hline PBEh1PBE & 5.58 & 7.27 & 2.04 & 0.62 & 2.29 & 251 & 1.75 \\
\hline PW91P86 & 4.64 & 7.89 & 3.1 & 0.94 & 2.24 & 282 & 2.4 \\
\hline PW91PW91 & 4.49 & 7.71 & 2.92 & 0.79 & 2.24 & 278 & 2.27 \\
\hline Experiment $^{\mathrm{a})}$ & \multicolumn{2}{|c|}{7.36} & & & 2.23 & $273 \pm 1$ & $2.05 \pm 0.10$ \\
\hline \multicolumn{8}{|c|}{ Ni-Ni Dimer } \\
\hline LC-BLYP & 7.61 & 7.41 & 0.44 & 0.5 & 2.24 & 300 & 1.88 \\
\hline BLYP & 4.26 & 7.97 & 2.85 & 0.64 & 2.12 & 334 & 2.33 \\
\hline B3LYP & 5.61 & 7.9 & 2.37 & 0.7 & 2.08 & 361 & 1.25 \\
\hline B3PW91 & 5.52 & 7.88 & 2.21 & 0.69 & 2.08 & 363 & 1.13 \\
\hline M06L & 4.16 & 6.76 & 2.2 & 0.62 & 2.11 & 339 & 2.04 \\
\hline
\end{tabular}




\begin{tabular}{cccccccc} 
M062X & 6.06 & 6.87 & 1.65 & 0.79 & 2.1 & 359 & -0.61 \\
BHandHLYP & 6.12 & 6.33 & 1.53 & 0.61 & 2.05 & 392 & -0.61 \\
PBEPBE & 4.29 & 7.57 & 2.83 & 0.77 & 2.12 & 336 & 2.57 \\
PBEh1PBE & 5.64 & 7.61 & 2.11 & 0.69 & 2.07 & 369 & 0.96 \\
PW91P86 & 4.51 & 8.13 & 3.07 & 0.91 & 2.11 & 343 & 2.67 \\
PW91PW91 & 4.38 & 8.13 & 2.9 & 0.77 & 2.11 & 339 & 2.56 \\
Experiment $^{\text {a) }}$ & $\mathbf{7 . 3 6}$ & & & $\mathbf{2 . 2 0}$ & $\mathbf{2 8 0 \pm 2 0}$ & $\mathbf{2 . 0 6 8 \pm 0 . 0 1}$ \\
\hline
\end{tabular}

The optimized geometries of copper clusters, $\mathrm{Cu}_{n}(n=3-13)$, in the ground state are presented with the electronic term in Figure 1. Note that $\mathrm{Cu}_{3}$ to $\mathrm{Cu}_{6}$ have 2D (two dimensional) structures, while $\mathrm{Cu}_{7}$ to $\mathrm{Cu}_{13}$ have $3 \mathrm{D}$ (three dimensional) structures. The minimum and maximum $\mathrm{Cu}-\mathrm{Cu}$ bond lengths ( $R_{\min }$ and $R_{\max }$, respectively) for each cluster size are shown in Table 2. As the cluster size grows, the $\mathrm{Cu}-\mathrm{Cu}$ bond lengths increase ranging from $2.252 \AA$ to $2.660 \AA$. It was found that the three-dimensional clusters approach to the experimental $\mathrm{Cu}-\mathrm{Cu}$ distance of bulk, $2.556 \AA$.

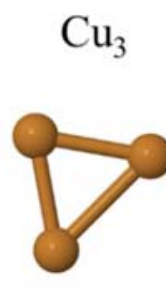

${ }^{2} \mathrm{~B}_{2}$

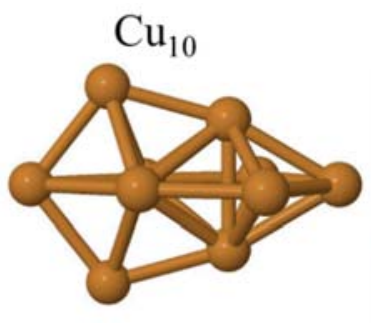

${ }^{1} \mathrm{~A}_{1}$

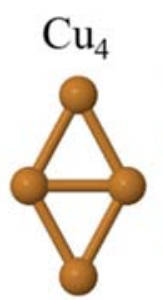

${ }^{1} \mathrm{~A}_{\mathrm{g}}$
${ }^{2} \mathrm{~A}_{1}$

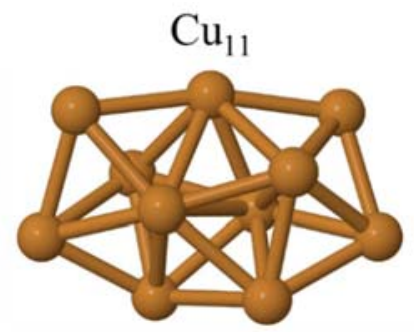

${ }^{2} \mathrm{~B}$

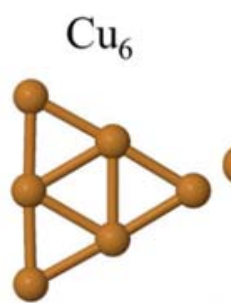

${ }^{1} \mathrm{~A}_{1}{ }^{\prime}$

${ }^{2} \mathrm{~A}_{2}{ }^{\prime \prime}$

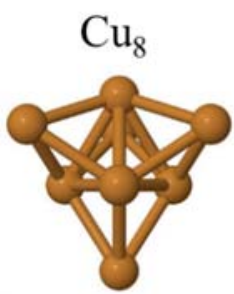

${ }^{1} \mathrm{~A}_{1}$

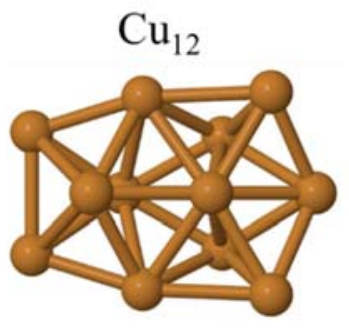

${ }^{1} \mathrm{~A}^{\prime}$

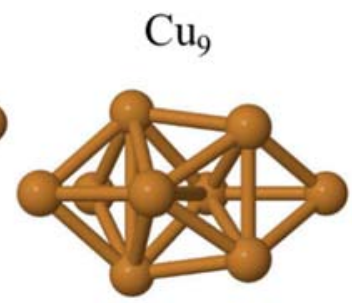

${ }^{2} \mathrm{~A}^{\prime}$

Figure 1. The lowest energy structures of the $\mathrm{Cu}_{n}(n=3-13)$ clusters and their corresponding electronic states. 
Table 2. The minimum and maximum bond lengths $\left(R_{\min }, R_{\max }\right)$ in $\AA$ for the most stable structures of the $\mathrm{Cu}_{n}, \mathrm{NiCu}_{n-1}$ and $\mathrm{Ni}_{2} \mathrm{Cu}_{n-2}(n=3-13)$ clusters.

\begin{tabular}{|c|c|c|c|c|c|}
\hline \multirow[t]{2}{*}{ Cluster } & \multicolumn{2}{|c|}{$\mathrm{Cu}-\mathrm{Cu}$} & \multicolumn{2}{|c|}{$\mathrm{Ni}-\mathrm{Cu}$} & \multirow{2}{*}{$\begin{array}{c}\mathrm{Ni}-\mathrm{Ni} \\
\quad R\end{array}$} \\
\hline & $R_{\min }$ & $R_{\max }$ & $R_{\min }$ & $R_{\max }$ & \\
\hline $\mathrm{Cu}_{3}$ & 2.28 & 2.6 & & & \\
\hline $\mathrm{Cu}_{4}$ & 2.25 & 2.4 & & & \\
\hline $\mathrm{Cu}_{5}$ & 2.36 & 2.43 & & & \\
\hline $\mathrm{Cu} 6$ & 2.36 & 2.43 & & & \\
\hline $\mathrm{Cu}_{7}$ & 2.43 & 2.48 & & & \\
\hline $\mathrm{Cu} 8$ & 2.43 & 2.45 & & & \\
\hline $\mathrm{Cu}_{9}$ & 2.39 & 2.57 & & & \\
\hline $\mathrm{Cu}_{10}$ & 2.41 & 2.53 & & & \\
\hline $\mathrm{Cu}_{11}$ & 2.41 & 2.6 & & & \\
\hline $\mathrm{Cu}_{12}$ & 2.38 & 2.66 & & & \\
\hline $\mathrm{Cu}_{13}$ & 2.4 & 2.58 & & & \\
\hline $\mathrm{NiCu}_{2}$ & 2.27 & 2.27 & 2.31 & 2.58 & \\
\hline $\mathrm{NiCu}_{3}$ & 2.41 & 2.41 & 2.26 & 2.41 & \\
\hline $\mathrm{NiCu}_{4}$ & 2.38 & 2.42 & 2.36 & 2.39 & \\
\hline $\mathrm{NiCu}_{5}$ & 2.36 & 2.43 & 2.37 & 2.44 & \\
\hline $\mathrm{NiCu}_{6}$ & 2.43 & 2.47 & 2.42 & 2.49 & \\
\hline $\mathrm{NiCu}_{7}$ & 2.42 & 2.46 & 2.43 & 2.49 & \\
\hline $\mathrm{NiCu}_{8}$ & 2.39 & 2.49 & 2.42 & 2.49 & \\
\hline $\mathrm{NiCu}_{9}$ & 2.41 & 2.56 & 2.39 & 2.51 & \\
\hline $\mathrm{NiCu}_{10}$ & 2.42 & 2.6 & 2.4 & 2.47 & \\
\hline $\mathrm{NiCu}_{11}$ & 2.41 & 2.66 & 2.38 & 2.46 & \\
\hline $\mathrm{NiCu}_{12}$ & 2.42 & 2.6 & 2.39 & 2.51 & \\
\hline $\mathrm{Ni}_{2} \mathrm{Cu}$ & & & 2.29 & 2.3 & 2.62 \\
\hline $\mathrm{Ni}_{2} \mathrm{Cu}_{2}$ & 2.39 & 2.39 & 2.27 & 2.41 & 2.42 \\
\hline $\mathrm{Ni}_{2} \mathrm{Cu}_{3}$ & 2.38 & 2.44 & 2.36 & 2.41 & 2.37 \\
\hline $\mathrm{Ni}_{2} \mathrm{Cu}_{4}$ & 2.35 & 2.35 & 2.37 & 2.43 & 2.12 \\
\hline $\mathrm{Ni}_{2} \mathrm{Cu}_{5}$ & 2.45 & 2.48 & 2.43 & 2.44 & 2.49 \\
\hline $\mathrm{Ni}_{2} \mathrm{Cu}_{6}$ & 2.44 & 2.47 & 2.43 & 2.45 & 2.53 \\
\hline $\mathrm{Ni}_{2} \mathrm{Cu}_{7}$ & 2.41 & 2.59 & 2.35 & 2.65 & 2.37 \\
\hline $\mathrm{Ni}_{2} \mathrm{Cu} 8$ & 2.43 & 2.57 & 2.39 & 2.48 & 2.43 \\
\hline
\end{tabular}




\begin{tabular}{cccccc}
$\mathrm{Ni}_{2} \mathrm{Cu} 9$ & 2.43 & 2.61 & 2.4 & 2.49 & 2.44 \\
$\mathrm{Ni}_{2} \mathrm{Cu}_{10}$ & 2.42 & 2.65 & 2.4 & 2.54 & 2.45 \\
$\mathrm{Ni}_{2} \mathrm{Cu}_{11}$ & 2.4 & 2.6 & 2.39 & 2.51 & 2.42 \\
\hline
\end{tabular}

When a single $\mathrm{Ni}$ atom is doped into the most stable structure of $\mathrm{Cu}_{n}$ clusters, many isomers are possible. Figure 2 shows the lowest energy optimized structures of the $\mathrm{NiCu}_{n-1}$ clusters $(n=3-13)$ with their corresponding electronic terms. It is worth pointing out that $\mathrm{NiCu}_{n-1}$ geometries are very similar to those of $\mathrm{Cu}_{n}(n=3-13)$. In a case of copper clusters, odd-numbered clusters have the doublet and even-numbered clusters have the singlet ground state while the odd-numbered and even-numbered $\mathrm{NiCu}_{n-1}(n=3-13)$ clusters prefer to have the triplet and doublet spin states, respectively. In these clusters, mainly two different bond lengths (Ni-Cu and $\mathrm{Cu}-\mathrm{Cu}$ ) are obtained, and Table 2 shows that $\mathrm{NiCu}_{3}$ has the minimum Ni$\mathrm{Cu}$ bond length, $2.26 \AA$, and $\mathrm{NiCu}_{2}$ has the maximum $\mathrm{Ni}-\mathrm{Cu}$ bond length, $2.58 \AA$. On the other hand, the $\mathrm{NiCu}_{2}$ has the shortest $\mathrm{Cu}-\mathrm{Cu}$ bond length of $2.27 \AA$ and the $\mathrm{NiCu}_{11}$ cluster has the longest $\mathrm{Cu}-\mathrm{Cu}$ bond length of $2.66 \AA$. 


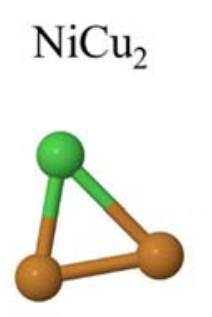

${ }^{3} \mathrm{~A}^{\prime}$

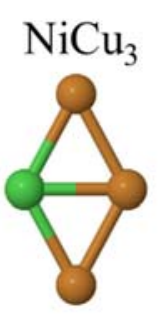

${ }^{2} \mathrm{~A}_{1}$

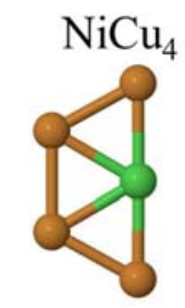

${ }^{3} \mathrm{~A}_{1}$

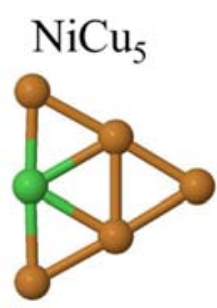

${ }^{2} \mathrm{~A}_{1}$

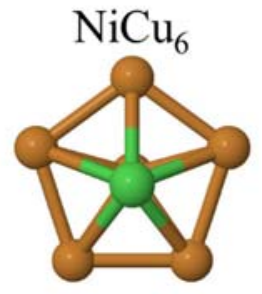

${ }^{3} \mathrm{~A}$

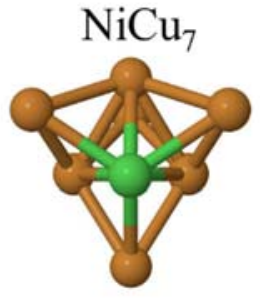

${ }^{2} \mathrm{~A}$

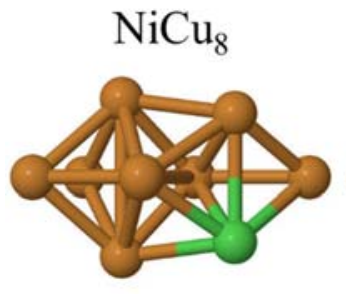

${ }^{3} \mathrm{~A}$

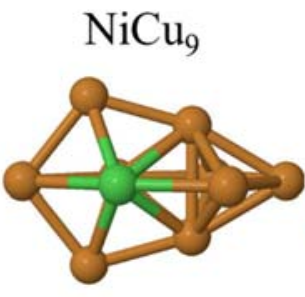

${ }^{2} \mathrm{~A}^{\prime}$

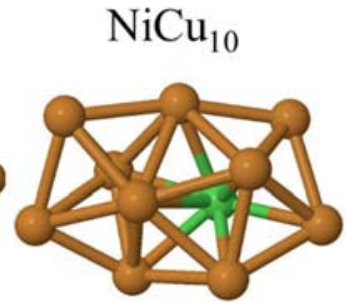

${ }^{3} \mathrm{~A}$

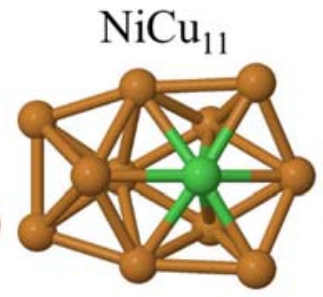

${ }^{2} \mathrm{~A} "$

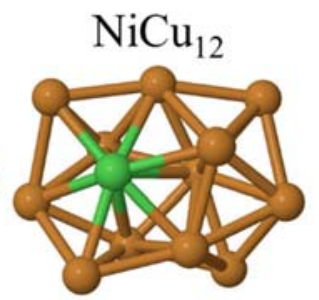

${ }^{3} \mathrm{~A}$

Figure 2. The lowest energy structures of the $\mathrm{NiCu}_{n-1}(n=3-13)$ clusters and their corresponding electronic states. The brown and green color represent $\mathrm{Cu}$ and $\mathrm{Ni}$ atom, respectively.

Figure 3 shows the most stable isomers for $\mathrm{Ni}_{2} \mathrm{Cu}_{n-2}(n=3-13)$ with the electronic terms, where two Ni atoms are doped to the most stable structure of $\mathrm{Cu}_{n}$ clusters. It is noted that geometries of $\mathrm{Ni}_{2} \mathrm{Cu}_{n-2}$ are also similar to those of $\mathrm{Cu}_{n}$. Here, $\mathrm{Ni}_{2} \mathrm{Cu}, \mathrm{Ni}_{2} \mathrm{Cu}_{3}, \mathrm{Ni}_{2} \mathrm{Cu}_{5}$, and $\mathrm{Ni}_{2} \mathrm{Cu} 9$ are quartet in the ground state, while $\mathrm{Ni}_{2} \mathrm{Cu}_{2}, \mathrm{Ni}_{2} \mathrm{Cu}_{4}, \mathrm{Ni}_{2} \mathrm{Cu}_{6}$, and $\mathrm{Ni}_{2} \mathrm{Cu}_{8}$ are triplet in the ground state. However, $\mathrm{Ni}_{2} \mathrm{Cu}_{7}$ and $\mathrm{Ni}_{2} \mathrm{Cu}_{11}$ are doublet in the ground state, which is lying $0.03 \mathrm{eV}$ below the quartet state, whereas $\mathrm{Ni}_{2} \mathrm{Cu}_{10}$ is quintet with the triplet lying only $0.33 \mathrm{eV}$ above and the septet is just $1.36 \mathrm{eV}$ above the quintet. The relative energies of the clusters in different spin states are given in Figures S2-S4 (in supporting information). In Table 2, three different types of bond lengths, namely, $\mathrm{Ni}-\mathrm{Ni}, \mathrm{Ni}-\mathrm{Cu}$ and $\mathrm{Cu}-\mathrm{Cu}$ are tabulated for $\mathrm{Ni}_{2} \mathrm{Cu}_{n-2}(n$ $=3-13)$. The Ni-Ni bond length has the longest $(2.62 \AA)$ and shortest $(2.12 \AA)$ for $\mathrm{Ni}_{2} \mathrm{Cu}$ and $\mathrm{Ni}_{2} \mathrm{Cu}_{4}$, respectively. In general, as the structure changes from $1 \mathrm{D}$ to $2 \mathrm{D}$ and from $2 \mathrm{D}$ to $3 \mathrm{D}$, Ni-Ni bond lengths decrease while Ni-Cu bond lengths increase from $2.27 \AA$ to $2.65 \AA$ and the 
$\mathrm{Cu}-\mathrm{Cu}$ bond lengths change from $2.35 \AA$ to $2.65 \AA$. The optimized parameters are compiled in

Tables S1-S3 (in supporting information).

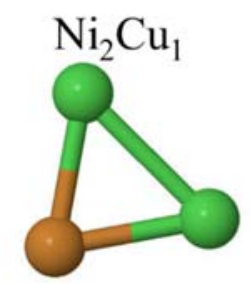

${ }^{4} \mathrm{~A} "$

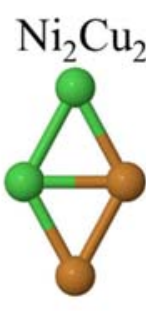

${ }^{3} \mathrm{~A}^{\prime}$

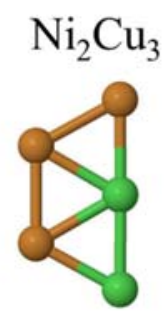

${ }^{4} \mathrm{~A} "$

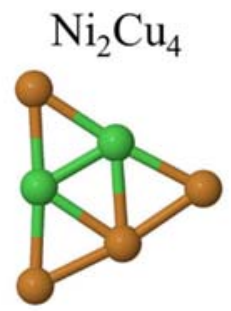

${ }^{3} \mathrm{~A} "$

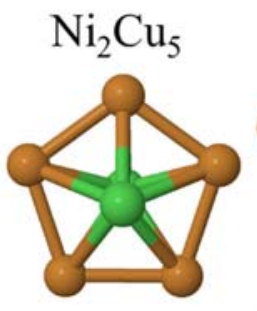

${ }^{4} \mathrm{~A}$

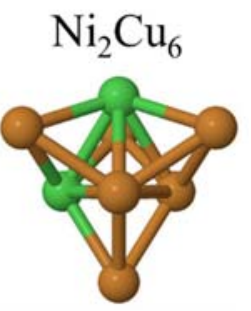

${ }^{3} \mathrm{~A}$

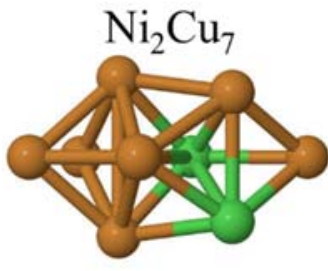

${ }^{2} \mathrm{~A}$

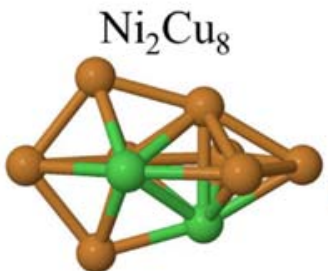

${ }^{3} \mathrm{~B}$

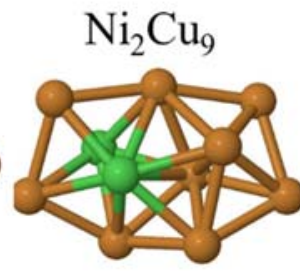

${ }^{4} \mathrm{~A}$

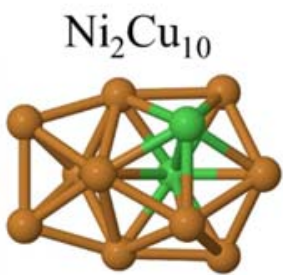

${ }^{5} \mathrm{~A}$

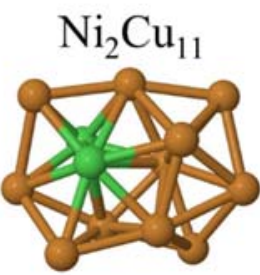

${ }^{2} \mathrm{~A}$

Figure 3. The lowest energy structures of the $\mathrm{Ni}_{2} \mathrm{Cu}_{n-2}(n=3-13)$ clusters and their corresponding electronic states. The brown and green color represent $\mathrm{Cu}$ and $\mathrm{Ni}$ atom, respectively.

Recently, Lin et al. ${ }^{6}$ employed a combination of far-infrared multiple photon dissociation (FIR-MPD) spectroscopy and quantum chemical calculations to determine the structures of small isolated yttrium-doped gold clusters $\operatorname{Au}_{n} \mathrm{Y}(n=1-9)$. Consequently, the computed vibrational spectra of the lowest energy $\mathrm{Cu}_{n}, \mathrm{NiCu}_{n-1}$ and $\mathrm{Ni}_{2} \mathrm{Cu}_{n-2}(n=2-13)$ clusters are shown in Figure 4. The $\mathrm{Cu}_{2}$ and $\mathrm{Ni}_{2}$ dimers have no absorption peaks because these dimers merely have a stretching vibration without change of a dipole moment. With regard to the clusters having planar or highly symmetrical geometries, the absorbed peaks are less than those of others. In case of Ni-doped copper clusters, the characteristic frequencies appeared in a higher region than the counter part of the pure copper clusters. The vibrational fundamentals of all the clusters are observed in the range of 5 to $350 \mathrm{~cm}^{-1}$. 

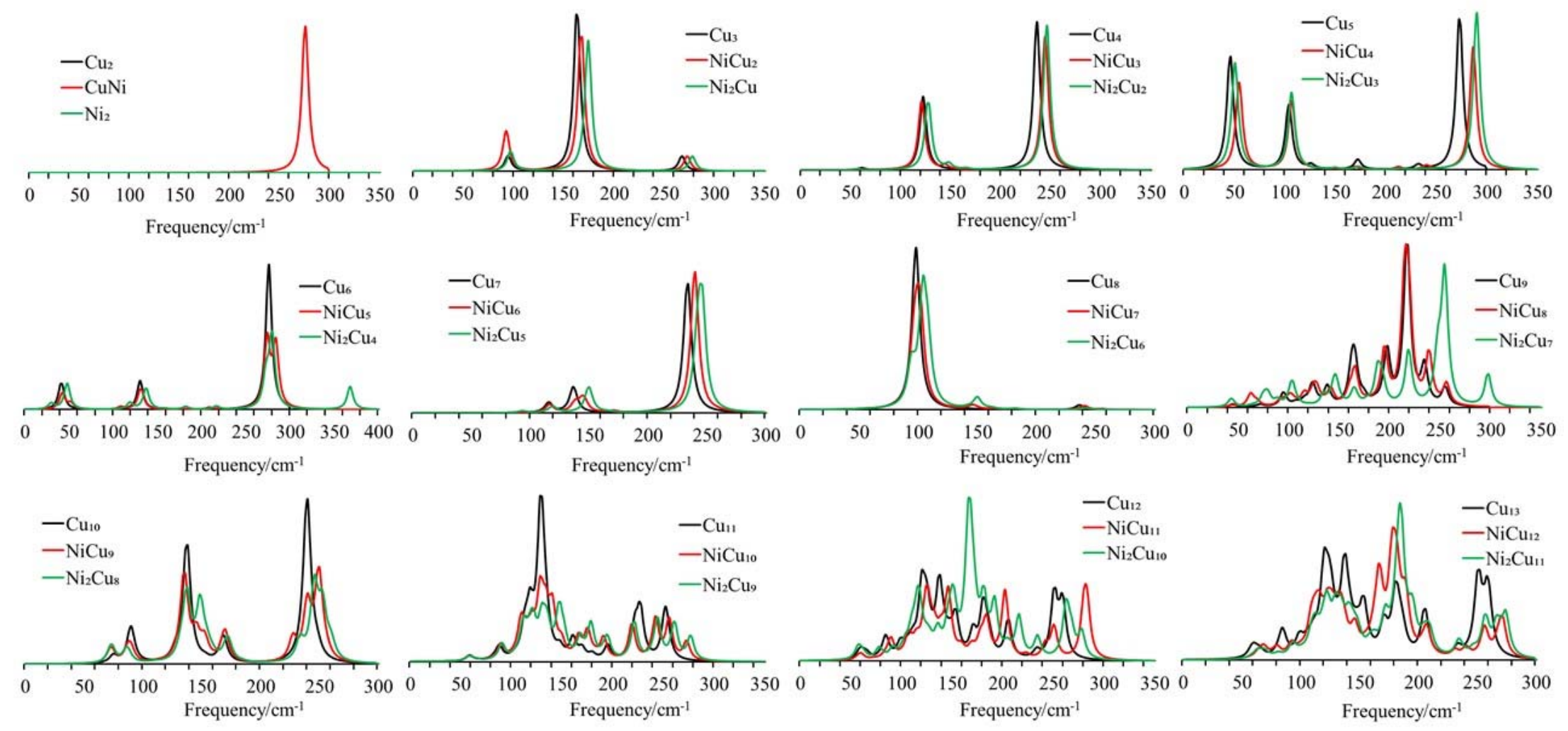

Figure 4. Computed vibrational spectra of the lowest energy structures of the $\mathrm{Cu}_{n}, \mathrm{NiCu}_{n-1}$ and $\mathrm{Ni}_{2} \mathrm{Cu}_{n-2}(n=2-13)$ clusters are plotted with $2 \mathrm{~cm}^{-1}$ infrared (IR) peak full width at half-height, and the peaks intensities have been extracted here in multiple of $10^{-40} \mathrm{esu}^{2} \mathrm{~cm}^{2}$. 


\section{Relative Stabilities}

In order to predict and compare the relative stabilities of the lowest energy structures of the clusters, it is significant to compute the binding energy per atom $\left(E_{\mathrm{BE}}\right)$. This can be defined as follows

$$
\begin{aligned}
& E_{\mathrm{BE}}\left(\mathrm{Cu}_{n}\right)=\frac{n E_{\mathrm{Cu}}-E_{\mathrm{Cu}_{n}}}{n} \\
& E_{\mathrm{BE}}\left(\mathrm{NiCu}_{n-1}\right)=\frac{(n-1) E_{\mathrm{Cu}}+E_{\mathrm{Ni}_{i}}-E_{\mathrm{NiCu}_{n-1}}}{n+1} \\
& E_{\mathrm{BE}}\left(\mathrm{Ni}_{2} \mathrm{Cu}_{n-2}\right)=\frac{(n-2) E_{\mathrm{Cu}}+2 E_{\mathrm{Ni}_{i}}-E_{\mathrm{Ni}_{2} \mathrm{Cu}_{n-2}}}{n+2}
\end{aligned}
$$

where $E_{\mathrm{Cu}}, E_{\mathrm{Cu}_{n}}, E_{\mathrm{Ni}}, E_{\mathrm{NiCu}_{n-1}}, E_{\mathrm{Ni}_{2} \mathrm{Cu}_{n-2}}$ denote the total energy of $\mathrm{Cu}$ atom, $\mathrm{Cu}_{n}$, Ni atom, $\mathrm{NiCu}_{n-1}$ and $\mathrm{Ni}_{2} \mathrm{Cu}_{n-2}$, respectively. The calculated binding energies per atom for the lowest energy structures of the $\mathrm{Cu}_{n}, \mathrm{NiCu}_{n-1}$ and $\mathrm{Ni}_{2} \mathrm{Cu}_{n-2}$ clusters are shown in Figure 5. The results indicate that $E_{\mathrm{BE}}$ increases as a function of the number of atoms in clusters and at $n=9$, the clusters possess relatively lower binding energies than the clusters at $n=8 . E_{\mathrm{BE}}$ of the single Ni-doped copper clusters is greater than $E_{\mathrm{BE}}$ of pure copper clusters, but lower than those of the doubly Ni-doped copper clusters. This implies that the doped clusters can continue to gain an energy during the growth process. 

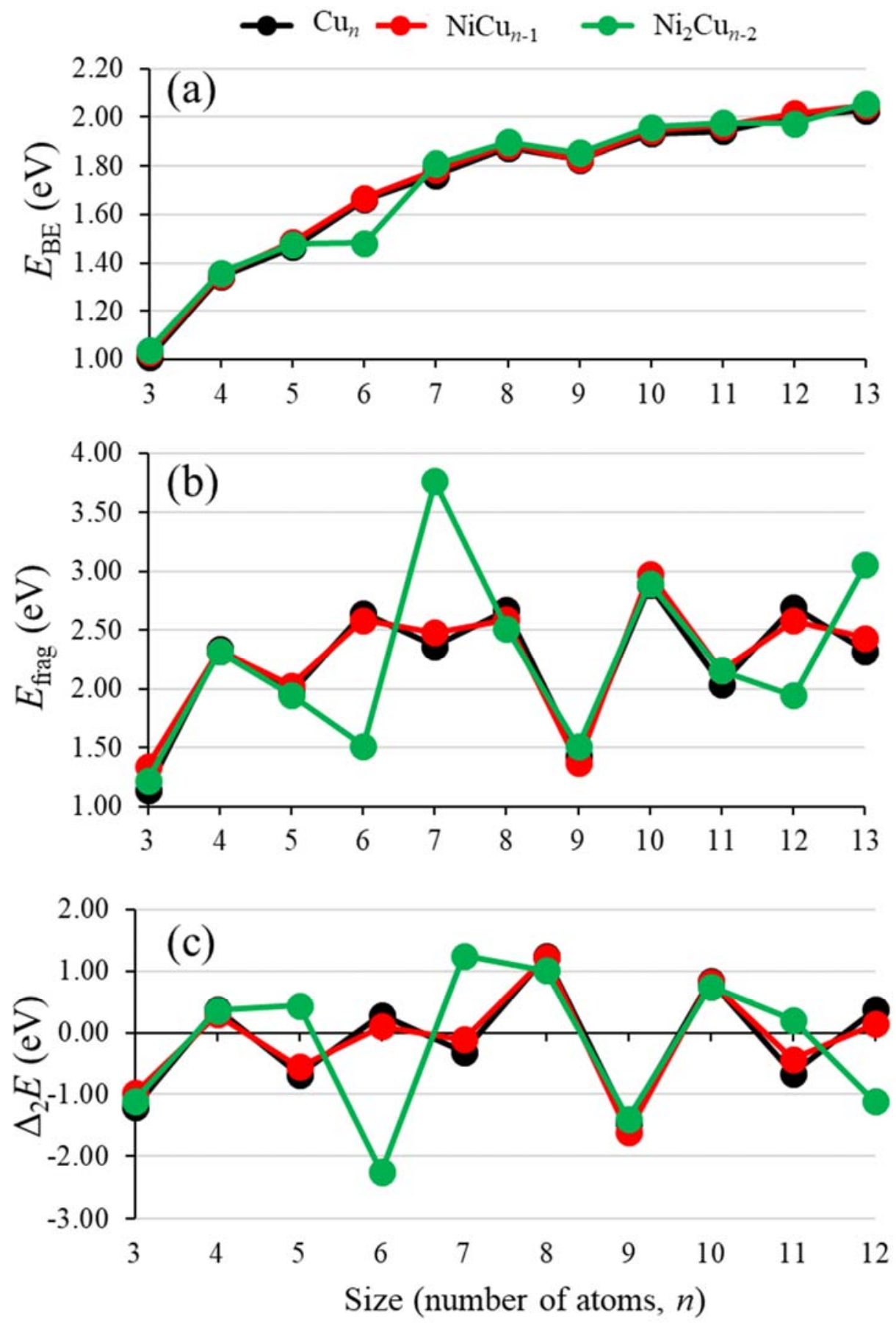

Figure 5. (a) Averaged binding energy $\left(E_{\mathrm{BE}}\right)$, (b) fragmentation energies $\left(E_{\mathrm{frag}}\right)$, and (c) size dependence of the second-order energy difference $\left(\Delta_{2} E\right)$ for the lowest energy structures of the $\mathrm{Cu}_{n}, \mathrm{NiCu}_{n-1}$ and $\mathrm{Ni}_{2} \mathrm{Cu}_{n-2}(n=3-13)$ clusters. 
Another parameter to understand the stability of the cluster is the fragmentation energies ( $\left.E_{\text {frag }}\right)$. Fragmentation processes may involve dissociation barriers. However, from a purely energetic point of view, the fragmentation energies $\left(E_{\text {frag }}\right)$ of the most stable clusters can be expressed as

$$
\begin{aligned}
& E_{\text {frag }}\left(\mathrm{Cu}_{n}\right)=E_{\mathrm{Cu}_{n-1}}+E_{\mathrm{Cu}}-E_{\mathrm{Cu}_{n}} \\
& E_{\text {frag }}\left(\mathrm{NiCu}_{n-1}\right)=E_{\mathrm{NiCu}_{n-2}}+E_{\mathrm{Cu}}-E_{\mathrm{NiCu}_{n-1}} \\
& E_{\text {frag }}\left(\mathrm{Ni}_{2} \mathrm{Cu}_{n-2}\right)=E_{\mathrm{Ni}_{2} \mathrm{Cu}_{n-3}}+E_{\mathrm{Cu}}-E_{\mathrm{Ni}_{2} \mathrm{Cu}_{n-2}}
\end{aligned}
$$

Where $E_{\mathrm{Cu}_{n-1}}$ and $E_{\mathrm{Ni}_{2} \mathrm{Cu}_{n-3}}$ are the total energy of the $\mathrm{Cu}_{n-1}$ and $\mathrm{Ni}_{2} \mathrm{Cu}_{n-3}$ clusters, respectively. When the fragmentation energies are negative, the parent clusters are unstable and could dissociate spontaneously by releasing an energy of $\left|E_{\text {frag }}\right|$. In this work, all the clusters have positive fragmentation energies, implying that the parent clusters are stable and one must supply energy to induce fragmentations. Generally, a higher fragmentation energy leads to lower the stability of the cluster.

The $E_{\text {frag }}$ values for the lowest energy structures of $\mathrm{Cu}_{n}, \mathrm{NiCu}_{n-1}$ and $\mathrm{Ni}_{2} \mathrm{Cu}_{n-2}$ as a function of cluster size are shown in Figure 5. It is found that the $\mathrm{Cu}_{3}, \mathrm{NiCu}_{2}$ and $\mathrm{Ni}_{2} \mathrm{Cu}$ clusters have the lowest fragmentation energies while $\mathrm{Cu}_{10}, \mathrm{NiCu}_{9}$ and $\mathrm{Ni}_{2} \mathrm{Cu}_{5}$ have the largest fragmentation energies of $2.88 \mathrm{eV}, 2.98 \mathrm{eV}$ and $3.76 \mathrm{eV}$, respectively.

In cluster physics, the second-order energy difference $\left(\Delta_{2} E\right)$ is used to measure the relative stabilities of the most stable clusters. For $\mathrm{Cu}_{n}, \mathrm{NiCu}_{n-1}$ and $\mathrm{Ni}_{2} \mathrm{Cu}_{n-2}$ clusters in the ground state, $\Delta_{2} E$ can be calculated as

$$
\begin{aligned}
& \Delta_{2} E_{\mathrm{Cu}_{n}}=E_{\mathrm{Cu}_{n-1}}+E_{\mathrm{Cu}_{n+1}}-2 E_{\mathrm{Cu}_{n}} \\
& \Delta_{2} E_{\mathrm{NiCu}_{n-1}}=E_{\mathrm{NiCu}_{n-2}}+E_{\mathrm{NiCu}_{n}}-2 E_{\mathrm{NiCu}_{n-1}}
\end{aligned}
$$




$$
\Delta_{2} E_{\mathrm{Ni}_{2} \mathrm{Cu}_{n-2}}=E_{\mathrm{Ni}_{2} \mathrm{Cu}_{n-3}}+E_{\mathrm{Ni}_{2} \mathrm{Cu}_{n-1}}-2 E_{\mathrm{Ni}_{2} \mathrm{Cu}_{n-2}}
$$

where $E$ is the total energy of the ground-state clusters. The calculated second-order energy differences as a function of the cluster size are illustrated in Figure 5. It is obvious that the evennumbered clusters are more stable than the odd-numbered ones. However, the introduction of two $\mathrm{Ni}$ atoms into copper cluster alters the stability pattern of the host clusters significantly for the $5 \leq$ $n \leq 7$ and $n=11,12$. Therefore, three maxima are observed for $\mathrm{Ni}_{2} \mathrm{Cu}_{3}, \mathrm{Ni}_{2} \mathrm{Cu}_{5}$ and $\mathrm{Ni}_{2} \mathrm{Cu}_{6}$ clusters. 


\section{HOMO-LUMO Gaps and Charge Transfer}

The HOMO-LUMO gap is an important parameter to examine the chemical stability of the clusters. A large energy gap usually correlates with remarkable kinetic stability. The calculated values of the HOMO-LUMO energy gaps for the lowest energy structures of $\mathrm{Cu}_{n}, \mathrm{NiCu}_{n-1}$ and $\mathrm{Ni}_{2} \mathrm{Cu}_{n-2}$ clusters are plotted in Figure 6. It is interesting to notice that the energy gap trends are similar in all three cases with exceptions of $\mathrm{Ni}_{2} \mathrm{Cu}_{10}$ and $\mathrm{Ni}_{2} \mathrm{Cu}_{11}$ clusters. The chemical inertness increases from $1 \mathrm{D}$ to $2 \mathrm{D}$ clusters and then keeps decreasing as structural transitions from $2 \mathrm{D}$ to $3 \mathrm{D}$ clusters. The clusters containing seven atoms seem unique by showing more reactiveness among the clusters having $n$ values in the range of 2 to 8 because of highly symmetric geometry. However, the Ni-atom doping into the copper clusters reduces the chemical inertness and the results show that copper clusters doped with two $\mathrm{Ni}$-atoms are more reactive than those doped with a single Ni-atom and pure copper clusters. In the pure copper clusters, there is observed odd-even alternation in the HOMO-LUMO energy gaps because of the electron pairing effect. Moreover, in $\mathrm{Ni}_{2}$-doped copper clusters case, quartet, triplet and quintet are the ground states while in single Nidoped copper cluster, doublet and triplet are the most stable spin states for even-numbered and odd-numbered clusters, respectively. It means that higher spin states make the HOMO-LUMO gap narrower, and so $\mathrm{Ni}_{2} \mathrm{Cu}_{10}$ is the most reactive clusters because its spin state in the ground state is quintet. Similarly, the clusters with $n=6$ are the most inert clusters. 


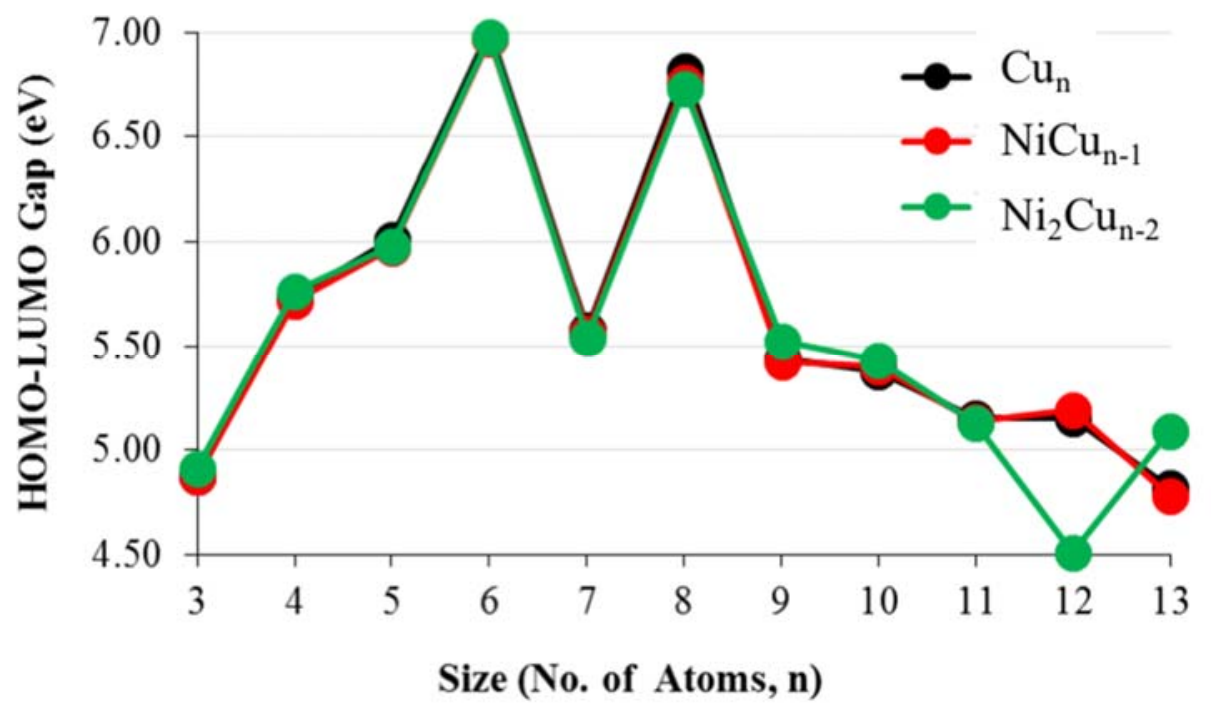

Figure 6. HOMO-LUMO gap of the lowest energy structures of the $\mathrm{Cu}_{n}, \mathrm{NiCu}_{n-1}$ and $\mathrm{Ni}_{2} \mathrm{Cu}_{n-2}(n$ $=3-13$ ) clusters.

The natural charges obtained in natural bond orbital (NBO) analyses ${ }^{69}$ for Ni-doped copper clusters can provide a reliable charge-transfer information. Here, natural charges of the dimers and $\mathrm{Ni}$ atoms in the most stable $\mathrm{NiCu}_{n-1}$ and $\mathrm{Ni}_{2} \mathrm{Cu}_{n-2}$ clusters were investigated. The calculated results are listed in Table $\mathbf{S 4}$. For the dimers case, $\mathrm{Cu}_{2}$ and $\mathrm{Ni}_{2}$ are neutral but in $\mathrm{CuNi}$ dimer, $\mathrm{Cu}$ and $\mathrm{Ni}$ atoms bear negative and positive charge of the same magnitude, respectively. It indicates that the charge transfer takes place from $\mathrm{Ni}$ atom to $\mathrm{Cu}$ atom though $\mathrm{Ni}$ atom has the larger electronegativity than that of the $\mathrm{Cu}$ atom. To make it clear, the natural electronic configurations given in Table $\mathbf{S} 4$ illustrate that $\mathrm{Ni}-4 \mathrm{~s}$ orbital donates charge to $\mathrm{Cu}-4 \mathrm{~s}$ orbital, making it an electron acceptor. On the contrary, charges are transferred from $\mathrm{Cu}$ atoms to the $\mathrm{Ni}$ atoms in $\mathrm{Ni}$-doped copper clusters of size larger than a dimer. 


\section{Electronic Properties}

The vertical ionization potential (VIP) and the vertical electron affinity (VEA) are two important factors to get insight into the electronic property and can be calculated as follows

$$
\begin{aligned}
& \mathrm{VIP}=E_{\text {cation }}-E_{\text {neutral }} \\
& \mathrm{VEA}=E_{\text {neutral }}-E_{\text {anion }}
\end{aligned}
$$

Where $E_{\text {cation }}$ and $E_{\text {anion }}$ are energies of the cationic and anionic systems, respectively, calculated at the optimized geometry of the neutral system with the energy $E_{\text {neutral. }}$ By introducing $E_{\text {HOMO }}$ (HOMO energy) and ELUMO (LUMO energy), the above equations can be rewritten using the Janak's theorem ${ }^{70}$ and the linearity condition for orbital energies ${ }^{71}$ as

$$
\begin{aligned}
& \mathrm{VIP}=-E_{\mathrm{HOMO}}=E_{\text {cation }}-E_{\text {neutral }} \\
& \mathrm{VEA}=-E_{\mathrm{LUMO}}=E_{\text {neutral }}-E_{\text {anion }}
\end{aligned}
$$

According to these equations, VIP and VEA were calculated for the lowest energy $\mathrm{Cu}_{n}, \mathrm{NiCu}_{n-1}$ and $\mathrm{Ni}_{2} \mathrm{Cu}_{n-2}$ clusters, which are shown in Table 3, along with the available experimental data. As an overall, the calculated VIPs of pure copper clusters show a very good agreement with the experimental values. ${ }^{72,73}$ HOMO and LUMO energies are a measure of the accuracy of DFT methods, and in this context, the excellent agreement for VIP and VEA confirms the reliability of the results. This indicates that the orbital energies by LC-DFT are reliable and can be used to predict the VIP and VEA. For odd-numbered clusters, the energy of LUMO for $\beta$-spin orbital represents VEA. 
Table 3. Vertical ionization potential (VIP) and vertical electron affinity (VEA) of the lowest energy structures for the $\mathrm{Cu}_{n}, \mathrm{NiCu}_{n-1}$ and $\mathrm{Ni}_{2} \mathrm{Cu}_{n-2}(n=3-13)$ clusters. Here $E_{\mathrm{N}}, E_{\mathrm{C}}$ and $E_{\mathrm{A}}$ represent the total energies of neutral, cation and anion clusters, respectively.

\begin{tabular}{|c|c|c|c|c|c|}
\hline Clusters & \multicolumn{3}{|c|}{ VIP (eV) } & \multicolumn{2}{c|}{ VEA (eV) } \\
\hline & $\boldsymbol{E}_{\mathbf{C}}-\boldsymbol{E}_{\mathbf{N}}$ & $-\mathbf{H O M O}$ & $\mathbf{E x p}{ }^{\text {a) }}$ & $\boldsymbol{E}_{\mathbf{N}} \boldsymbol{E}_{\mathbf{A}}$ & $-\mathbf{L U M}$ \\
\hline $\mathrm{Cu}_{3}$ & 5.53 & 5.63 & $5.80 \pm 0.05$ & 0.92 & 0.76 \\
\hline $\mathrm{Cu}_{4}$ & 6.32 & 6.52 & $7.15 \pm 0.75$ & 0.96 & 0.78 \\
\hline $\mathrm{Cu}_{5}$ & 6.03 & 6.31 & $6.30 \pm 0.05$ & 1.28 & 1.07 \\
\hline $\mathrm{Cu}_{6}$ & 7.06 & 7.45 & $7.15 \pm 0.75$ & 0.64 & 0.44 \\
\hline $\mathrm{Cu}_{7}$ & 5.65 & 5.95 & $6.07 \pm 0.05$ & 1.22 & 0.95 \\
\hline $\mathrm{Cu}_{8}$ & 6.85 & 7.27 & $7.15 \pm 0.75$ & 0.61 & 0.46 \\
\hline $\mathrm{Cu}_{9}$ & 5.85 & 6.16 & $5.36 \pm 0.05$ & 1.72 & 1.42 \\
\hline $\mathrm{Cu}_{10}$ & 5.67 & 6.01 & $6.07 \pm 0.05$ & 0.89 & 0.63 \\
\hline $\mathrm{Cu}_{11}$ & 5.62 & 5.96 & $5.91 \pm 0.05$ & 1.73 & 1.43 \\
\hline $\mathrm{Cu}_{12}$ & 5.91 & 6.3 & $6.30 \pm 0.05$ & 1.44 & 1.14 \\
\hline $\mathrm{Cu}_{13}$ & 5.34 & 5.7 & $5.66 \pm 0.05$ & 1.7 & 1.38 \\
\hline $\mathrm{Ni}_{2} \mathrm{Cu}_{4}$ & 5.52 & 5.66 & & 0.91 & 0.74 \\
\hline $\mathrm{Ni}_{2} \mathrm{Cu}_{2}$ & 7.75 & 6.51 & & 0.92 & 0.75 \\
\hline $\mathrm{Ni}_{2} \mathrm{Cu}_{3}$ & 5.92 & 6.28 & & 1.29 & 1.01 \\
\hline $\mathrm{Ni}_{2} \mathrm{Cu}_{4}$ & 5.84 & 7.4 & & 1.52 & 0.22 \\
\hline $\mathrm{Ni}_{2} \mathrm{Cu}_{5}$ & 5.56 & 5.87 & & 1.09 & 0.82 \\
\hline $\mathrm{Ni}_{2} \mathrm{Cu}_{6}$ & 6.51 & 7.16 & & 0.17 & 0.43 \\
\hline $\mathrm{Ni}_{2} \mathrm{Cu}_{7}$ & 5.61 & 6.69 & & 1.48 & 1.16 \\
\hline $\mathrm{Ni}_{2} \mathrm{Cu}_{8}$ & 5.56 & 6.02 & & 0.89 & 0.53 \\
\hline $\mathrm{Ni}_{2} \mathrm{Cu}_{9}$ & 5.51 & 5.85 & & 1.64 & 1.27 \\
\hline $\mathrm{Ni}_{2} \mathrm{Cu}_{10}$ & 4.98 & 5.35 & & 2.09 & 1.66 \\
\hline $\mathrm{Ni}_{2} \mathrm{Cu}_{11}$ & 7.17 & 6.39 & & 1.63 & 1.3 \\
\hline $\mathrm{NiCu}_{2}$ & 5.51 & 5.63 & & 0.92 & 0.75 \\
\hline $\mathrm{NiCu}_{3}$ & 6.3 & 6.49 & & 0.95 & 0.73 \\
\hline $\mathrm{NiCu}_{4}$ & 6.26 & 6.27 & & 1.22 & 1.01 \\
\hline & & & & & \\
\hline & & & & & \\
\hline
\end{tabular}




\begin{tabular}{|c|c|c|l|l|l|}
\hline $\mathrm{NiCu}_{5}$ & 7.14 & 7.4 & & 0.63 & 0.43 \\
\hline $\mathrm{NiCu}_{6}$ & 5.61 & 5.91 & & 1.18 & 0.88 \\
\hline $\mathrm{NiCu}_{7}$ & 6.56 & 7.2 & & 0.61 & 0.42 \\
\hline $\mathrm{NiCu}_{8}$ & 5.8 & 6.13 & & 1.75 & 1.36 \\
\hline $\mathrm{NiCu}_{9}$ & 7.82 & 6.02 & & 0.99 & 0.59 \\
\hline $\mathrm{NiCu}_{10}$ & 5.56 & 5.9 & & 1.68 & 1.33 \\
\hline $\mathrm{NiCu}_{11}$ & 5.56 & 6.31 & & 1.54 & 1.04 \\
\hline $\mathrm{NiCu}_{12}$ & 5.29 & 5.65 & & 1.67 & 1.28 \\
\hline
\end{tabular}

a) Refs. 72, 73 . 


\section{Reactivity Descriptors}

In conceptual density functional theory, chemical potential $(\mu)$, chemical hardness $(\eta)$ and electrophilicity index $(\omega)$ are indicators of the reactivity and stability. ${ }^{74}$ All of these are well established to represent global quantities in chemical reactivity and our interests here to exploit these concepts to rationalize the behavior of the clusters. Using a finite difference method ${ }^{75}$ and Koopmans theorem ${ }^{76}$, the formal expressions for chemical potential, chemical hardness and electrophilicity index are

$$
\begin{aligned}
& \mu=\frac{\text {-VIP-VEA }}{2}=\frac{\text { HOMO }+ \text { LUMO }}{2} \\
& \eta=\frac{\text { VIP }- \text { VEA }}{2}=\frac{\text { LUMO }- \text { HOMO }}{2} \\
& \omega=\frac{\mu^{2}}{\eta}
\end{aligned}
$$

The chemical potential measures the escaping tendency of the electrons from a system; the charge transfer from the higher $\mu$ of a system to the lower $\mu$ of another system takes place until the chemical potential becomes constant through the space. The chemical potential, derived from equation (14), for the lowest energy $\mathrm{Cu}_{n}, \mathrm{NiCu}_{n-1}$ and $\mathrm{Ni}_{2} \mathrm{Cu}_{n-2}(n=3-13)$ clusters are presented in Table 4. The chemical potential calculated on the basis of HOMO and the LUMO energies are given in the bracket. It is expected that the open-shell clusters will have maximum values of $\mu$ and after one electron transfer, these systems will have a closed-shell, and the resulting systems will be more stable than the original open-shell clusters. In general, Table 5 shows that the odd-number open-shell clusters present higher values of $\mu$ than the even closed-shell neighboring clusters. Similar trends are observed in all three kinds of clusters. When $\mathrm{Cu}$ atoms are replaced by $\mathrm{Ni}$ atoms, then the chemical potential of the clusters decrease with those of the pure copper clusters of the same size. However, some abnormal chemical potential, calculated on the basis of VIP and VEA 
values, were observed for $\mathrm{Ni}_{2} \mathrm{Cu}_{2}$ and $\mathrm{NiCu}_{9}$ clusters. We attribute this discrepancy due to somewhat overestimated total energies of the anionic clusters given by DFT methods. Overall, the $\mathrm{Ni}_{2} \mathrm{Cu}_{11}$ cluster has the lowest chemical potential and the clusters containing three atoms have the highest chemical potential. These results also seem to show that the chemical potential of the clusters calculated from HOMO and LUMO energies are in close agreement with those of the chemical potential derived from VIP and VEA. Therefore, HOMO and LUMO energies obtained by LC-DFT can be directly used not only to predict the chemical potential of the systems but also to check the correct values of VIP and VEA of the systems.

Table 4. Chemical potential $(\mu)$, chemical hardness $(\eta)$ and electrophilicity index $(\omega)$ of the lowest energy structures of the $\mathrm{Cu}_{n}, \mathrm{NiCu}_{n-1}$ and $\mathrm{Ni}_{2} \mathrm{Cu}_{n-2}(n=3-13)$ clusters, using the VIP and VEA values. The results in brackets were obtained using the HOMO and LUMO energies.

\begin{tabular}{cccc}
\hline \hline & \multicolumn{3}{c}{ Chemical Potential $(\mathrm{eV})$} \\
\cline { 2 - 4 }$n$ & $\mathrm{Cu}_{n}$ & $\mathrm{NiCu}_{n-1}$ & $\mathrm{Ni}_{2} \mathrm{Cu}_{n-2}$ \\
\hline \hline 3 & $-3.22(-3.20)$ & $-3.22(-3.19)$ & $-3.14(-3.20)$ \\
4 & $-3.64(-3.65)$ & $-3.63(-3.61)$ & $-4.33(-3.63)$ \\
5 & $-3.65(-3.69)$ & $-3.74(-3.64)$ & $-3.61(-3.65)$ \\
6 & $-3.85(-3.95)$ & $-3.88(-3.91)$ & $-3.68(-3.81)$ \\
7 & $-3.43(-3.45)$ & $-3.40(-3.40)$ & $-3.33(-3.34)$ \\
8 & $-3.73(-3.87)$ & $-3.58(-3.81)$ & $-3.34(-3.79)$ \\
9 & $-3.79(-3.79)$ & $-3.77(-3.75)$ & $-3.55(-3.93)$ \\
10 & $-3.28(-3.32)$ & $-4.40(-3.30)$ & $-3.22(-3.27)$ \\
11 & $-3.68(-3.69)$ & $-3.62(-3.62)$ & $-3.57(-3.56)$ \\
12 & $-3.68(-3.72)$ & $-3.55(-3.67)$ & $-3.53(-3.51)$ \\
13 & $-3.52(-3.54)$ & $-3.48(-3.46)$ & $-4.40(-3.85)$ \\
\hline
\end{tabular}

\section{Chemical Hardness (eV)}




\begin{tabular}{cccc}
$n$ & $\mathrm{Cu}_{n}$ & $\mathrm{NiCu}_{n-1}$ & $\mathrm{Ni}_{2} \mathrm{Cu}_{n-2}$ \\
\hline \hline 3 & $2.31(2.44)$ & $2.29(2.44)$ & $2.39(2.46)$ \\
4 & $2.68(2.87)$ & $2.67(2.88)$ & $3.41(2.88)$ \\
5 & $2.38(2.62)$ & $2.52(2.63)$ & $2.31(2.64)$ \\
6 & $3.21(3.50)$ & $3.26(3.49)$ & $2.16(3.59)$ \\
7 & $2.22(2.50)$ & $2.21(2.51)$ & $2.23(2.53)$ \\
8 & $3.12(3.41)$ & $2.98(3.39)$ & $3.17(3.36)$ \\
9 & $2.07(2.37)$ & $2.03(2.38)$ & $2.07(2.76)$ \\
10 & $2.39(2.69)$ & $3.41(2.72)$ & $2.34(2.75)$ \\
11 & $1.94(2.27)$ & $1.94(2.29)$ & $1.94(2.29)$ \\
12 & $2.23(2.58)$ & $2.01(2.64)$ & $1.44(1.84)$ \\
13 & $1.82(2.16)$ & $1.81(2.18)$ & $2.77(2.55)$ \\
\hline
\end{tabular}

\begin{tabular}{cccc}
\hline \hline & \multicolumn{3}{c}{ Electrophilicity Index $(\mathbf{e V})$} \\
\cline { 2 - 4 }$n$ & $\mathrm{Cu}_{n}$ & $\mathrm{NiCu}_{n-1}$ & $\mathrm{Ni}_{2} \mathrm{Cu}_{n-2}$ \\
\hline \hline 3 & $2.25(2.09)$ & $2.26(2.09)$ & $2.07(2.09)$ \\
4 & $2.47(2.32)$ & $2.46(2.26)$ & $2.75(2.29)$ \\
5 & $2.81(2.60)$ & $2.78(2.52)$ & $2.81(2.53)$ \\
6 & $2.31(2.22)$ & $2.32(2.20)$ & $3.13(2.02)$ \\
7 & $2.66(2.38)$ & $2.61(2.30)$ & $2.48(2.21)$ \\
8 & $2.23(2.19)$ & $2.16(2.14)$ & $1.76(2.14)$ \\
9 & $3.47(3.03)$ & $3.51(2.95)$ & $3.04(2.79)$ \\
10 & $2.25(2.05)$ & $2.84(2.01)$ & $2.22(1.95)$ \\
11 & $3.47(3.01)$ & $3.37(2.86)$ & $3.30(2.77)$ \\
12 & $3.03(2.69)$ & $3.14(2.56)$ & $4.33(3.34)$ \\
13 & $3.40(2.91)$ & $3.35(2.75)$ & $3.49(2.91)$ \\
\hline
\end{tabular}

The chemical hardness is a global molecular property and provides information about general feature of a reactive molecule. Therefore, the chemical hardness, $\eta$, of the most stable $\mathrm{Cu}_{n}$, $\mathrm{NiCu}_{n-1}$ and $\mathrm{Ni}_{2} \mathrm{Cu}_{n-2}(n=3-13)$ clusters are calculated using equation (15) which are listed in Table 4. The results obtained from HOMO and LUMO are shown inside the bracket. From Table 4, one can observe that the even-numbered clusters have higher values of hardness than their odd- 
numbered neighboring clusters. These trends are also similar to the fragmentation energy and the HOMO-LUMO energy gap trends as mentioned-above. In general, Ni-doping makes the clusters more inert against the host clusters. In addition, $\mathrm{Cu}_{13}, \mathrm{NiCu}_{12}$ and $\mathrm{Ni}_{2} \mathrm{Cu}_{10}$ clusters show the lowest chemical hardness in $\mathrm{Cu}_{n}, \mathrm{NiCu}_{n-1}$ and $\mathrm{Ni}_{2} \mathrm{Cu}_{n-2}(n=3-13)$ clusters, respectively.

The electrophilicity index, $\omega$, is another parameter to measure the electrophilic power of a system, just as, in classical electrostatics, power $=V^{2} / R$, and $\mu$ and $\eta$ serve the purpose of potential $(V)$ and resistance $(R)$, respectively. The relation among $\omega, \mu$ and $\eta$ are shown in equation (16). The computed $\omega$ for the clusters are given in Table 4. The results show that the $\mathrm{Ni}_{2} \mathrm{Cu}_{10}$ and $\mathrm{Ni}_{2} \mathrm{Cu}_{6}$ clusters have the highest and the lowest electrophilicity index, respectively. The Ni-doping into copper clusters affects the electrophilic power of the pure copper clusters. We have also checked the minimum electrophilicity principle ${ }^{77-79}$ for a small cluster containing three atoms, $\mathrm{NiCu}_{2}$, as given below in Table 5. This result indicates that the more stable structure has the lower electrophilicity value, hence the minimum electrophilicity principle is satisfied.

Table 5. The electrophilicity values for the $\mathrm{NiCu}_{2}$ clusters.

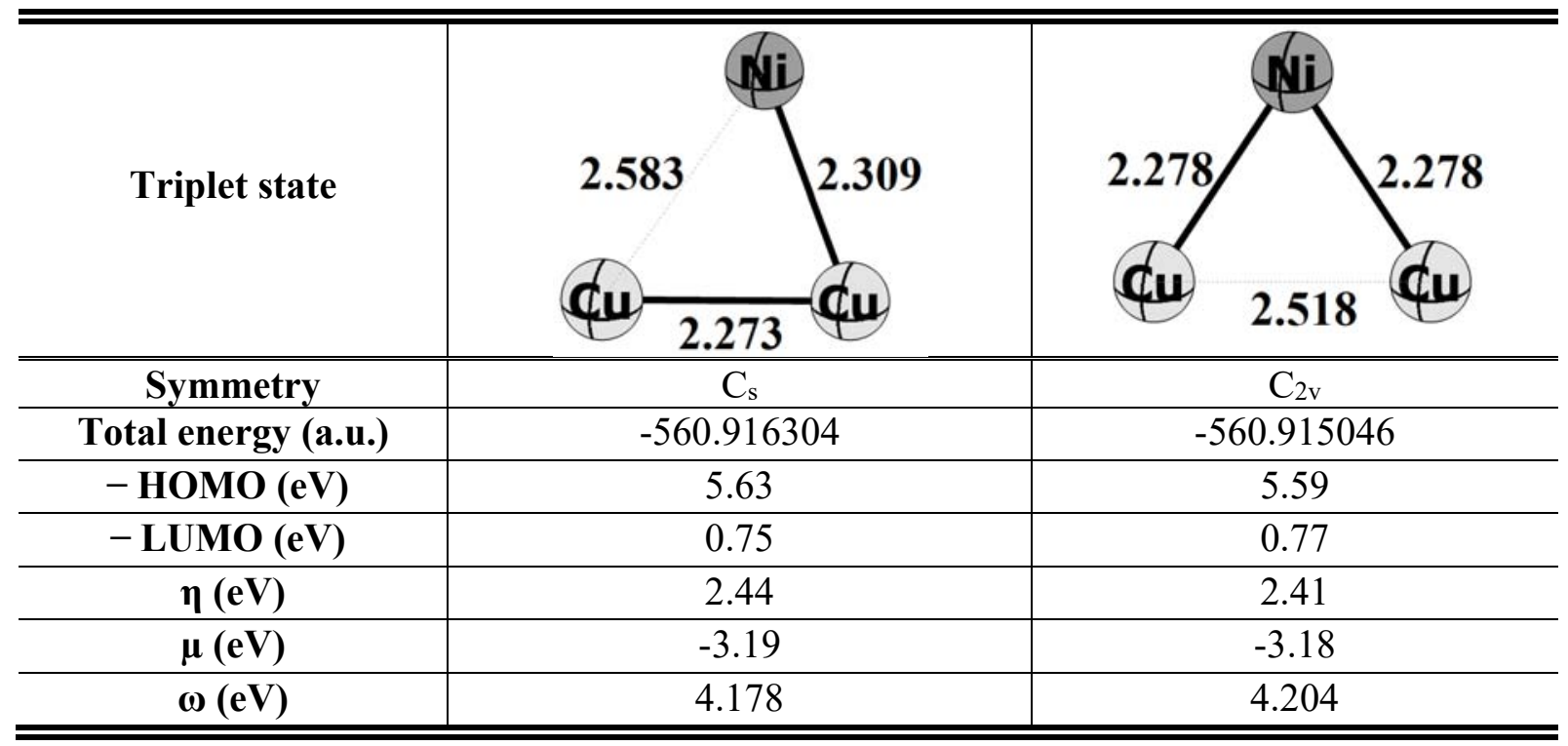




\section{Polarizability and the Minimum Polarizability Principle (MPP)}

The static polarizability is considered as one of the most important observables to measure the distortion of the electron density under the effect of an external static electric field. The average static polarizability, $<\alpha>$, is defined as ${ }^{74}$

$$
<\alpha>=\left(\alpha_{x x}+\alpha_{y y}+\alpha_{z z}\right) / 3
$$

In Table 6 we show the averaged static polarizability of the lowest energy structures of the $\mathrm{Cu}_{n}$, $\mathrm{NiCu}_{n-1}$ and $\mathrm{Ni}_{2} \mathrm{Cu}_{n-2}(n=3-13)$ clusters using equation (17). We note that as going from $n=3$ to $n=13$, the averaged static polarizability increases. The Ni-doping into pure copper clusters increases $\langle\alpha\rangle$ from $n=3$ to $n=8$ while opposite trends are observed from $n=9$ to $n=13$. All in all, the $\mathrm{Cu}_{13}$ cluster has the largest averaged static polarizability followed by $\mathrm{NiCu}_{12}$ and $\mathrm{Ni}_{2} \mathrm{Cu}_{11}$ clusters and $\mathrm{Cu}_{3}$ has the lowest averaged static polarizability.

Table 6. The averaged static polarizability, $\langle\boldsymbol{\alpha}\rangle$, in atomic units of the lowest energy structures of the $\mathrm{Cu}_{n}, \mathrm{NiCu}_{n-1}$ and $\mathrm{Ni}_{2} \mathrm{Cu}_{n-2}(n=3-13)$ clusters.

\begin{tabular}{cccc}
\hline \hline & \multicolumn{3}{c}{$<\boldsymbol{\alpha}>(\mathbf{a u})$} \\
\hline$n$ & $\mathrm{Cu}_{n}$ & $\mathrm{NiCu}_{n-1}$ & $\mathrm{Ni}_{2} \mathrm{Cu}_{n-2}$ \\
\hline \hline 3 & 142.69 & 145.23 & 147.30 \\
4 & 147.97 & 149.95 & 150.97 \\
5 & 189.08 & 191.35 & 194.73 \\
6 & 206.74 & 210.29 & 206.81 \\
7 & 240.13 & 240.45 & 241.53 \\
8 & 259.98 & 260.39 & 260.56 \\
9 & 307.16 & 309.71 & 304.12 \\
10 & 330.35 & 331.22 & 330.43 \\
11 & 365.09 & 362.69 & 363.00 \\
12 & 385.54 & 384.22 & 406.87 \\
13 & 420.43 & 417.77 & 415.07 \\
\hline \hline
\end{tabular}


In order to show the consistency between the energetics and electronic descriptors, we show a good linear relation between the binding energies per atom, $E_{B E}$, and the average static polarizability per atom, $<\alpha>/ n$, of the $\mathrm{Cu}_{n}, \mathrm{NiCu}_{n-1}$ and $\mathrm{Ni}_{2} \mathrm{Cu}_{n-2}(n=3-13)$ clusters in Figure 7 . The results show that $\mathrm{Cu}_{13}, \mathrm{NiCu}_{12}$ and $\mathrm{Ni}_{2} \mathrm{Cu}_{11}$ clusters have the largest $E_{B E}$ with minimum $<\alpha>/ n$ values in their corresponding classes of the clusters. Overall, $\mathrm{Ni}_{2} \mathrm{Cu}_{11}$ cluster has the largest averaged binding energies of $2.06 \mathrm{eV}$ at the lowest averaged static polarizability per atom value of 31.93 a.u. amongst all three kinds of clusters. This indicates that the clusters with strong bonds (or high electronic delocalization degree) present minimum values of a polarizability per atom, in agreement with the minimum polarizability principle (MPP) which states that ${ }^{74}$ 'the natural direction of evolution of any system is towards a state of minimum polarizability.' 

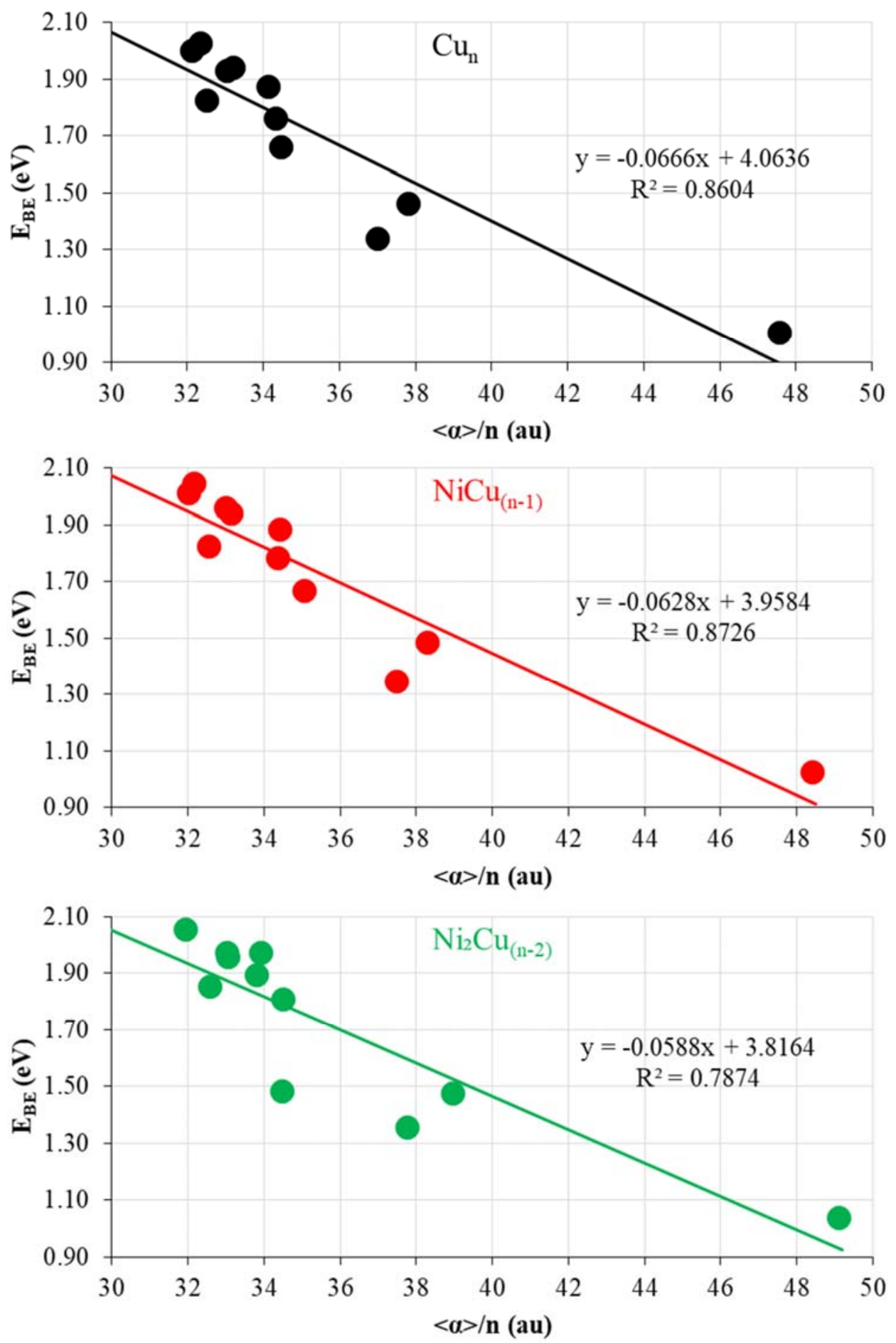

Figure 7. Correlation between the averaged binding energy $\left(E_{\mathrm{BE}}\right)$ and the averaged static polarizability per atom $(<\alpha>/ n)$ of the $\mathrm{Cu}_{n}, \mathrm{NiCu}_{n-1}$ and $\mathrm{Ni}_{2} \mathrm{Cu}_{n-2}(n=3-13)$ clusters. 


\section{Magnetic Properties}

The magnetic properties of the metal clusters are always important to make nano-electronic devices and high density magnetic storage materials. The total magnetic moment $\left(\mu_{\text {tot }}\right)$ in the Russel-Saunders scheme is a combination of a total spin magnetic moment $(S)$ and a total orbital magnetic moment $(L)$ which is defined as $\mu_{\text {tot }}=(2 S+L) \mu_{\mathrm{B}}\left(\mu_{\mathrm{B}}\right.$ is the Bohr magneton). In the Heisenberg model, one neglects the $L$ contribution and then $\mu_{\mathrm{tot}}=g_{\mathrm{e}} \mu_{\mathrm{B}} S$, where the gyromagnetic ratio $g_{\mathrm{e}}$ is 2.0023 . Therefore, we consider the total magnetic moment, $\mu_{\mathrm{tot}}=2 S \mu_{\mathrm{B}}$, to be equal to the $\left[n_{\alpha}-n_{\beta}\right] \mu_{\mathrm{B}}$, where $n_{\alpha}$ and $n_{\beta}$ are the total numbers of the up-spin and the down-spin, respectively.

The total magnetic moments and total magnetic moments per atom calculated for the lowest energy $\mathrm{Cu}_{n}, \mathrm{NiCu}_{n-1}$ and $\mathrm{Ni}_{2} \mathrm{Cu}_{n-2}(n=3-13)$ clusters are displayed in Figure 8. The lowest energy copper clusters show an odd-even alternation as a function of the cluster size, $n$, in the total magnetic moment. The magnetic moment for $\mathrm{Cu}_{n}$ clusters with even $n$ is completely quenched. For the single Ni-atom doped clusters, the magnetic moment is non-zero and is larger than that of the $\mathrm{Cu}_{n}$ clusters. In case of the doubly $\mathrm{Ni}$-atoms doped copper clusters, the magnetic moments become larger than that of $\mathrm{NiCu}_{n-1}$ clusters. However, for larger clusters, $\mathrm{Ni}_{2} \mathrm{Cu}$ and $\mathrm{Ni}_{2} \mathrm{Cu}_{11}$, the magnetic moment is equal to the magnetic moment of the $\mathrm{Cu}_{9}$ and $\mathrm{Cu}_{13}$ clusters, respectively, due to the preferred singlet spin state. The $\mathrm{Ni}_{2} \mathrm{Cu}_{10}$ cluster show the highest magnetic moment as it prefers the lowest energy in quintet spin state. In general, this result indicates that the substitution of $\mathrm{Ni}$-atoms for $\mathrm{Cu}$-atoms can enhance the magnetism of the host clusters. 

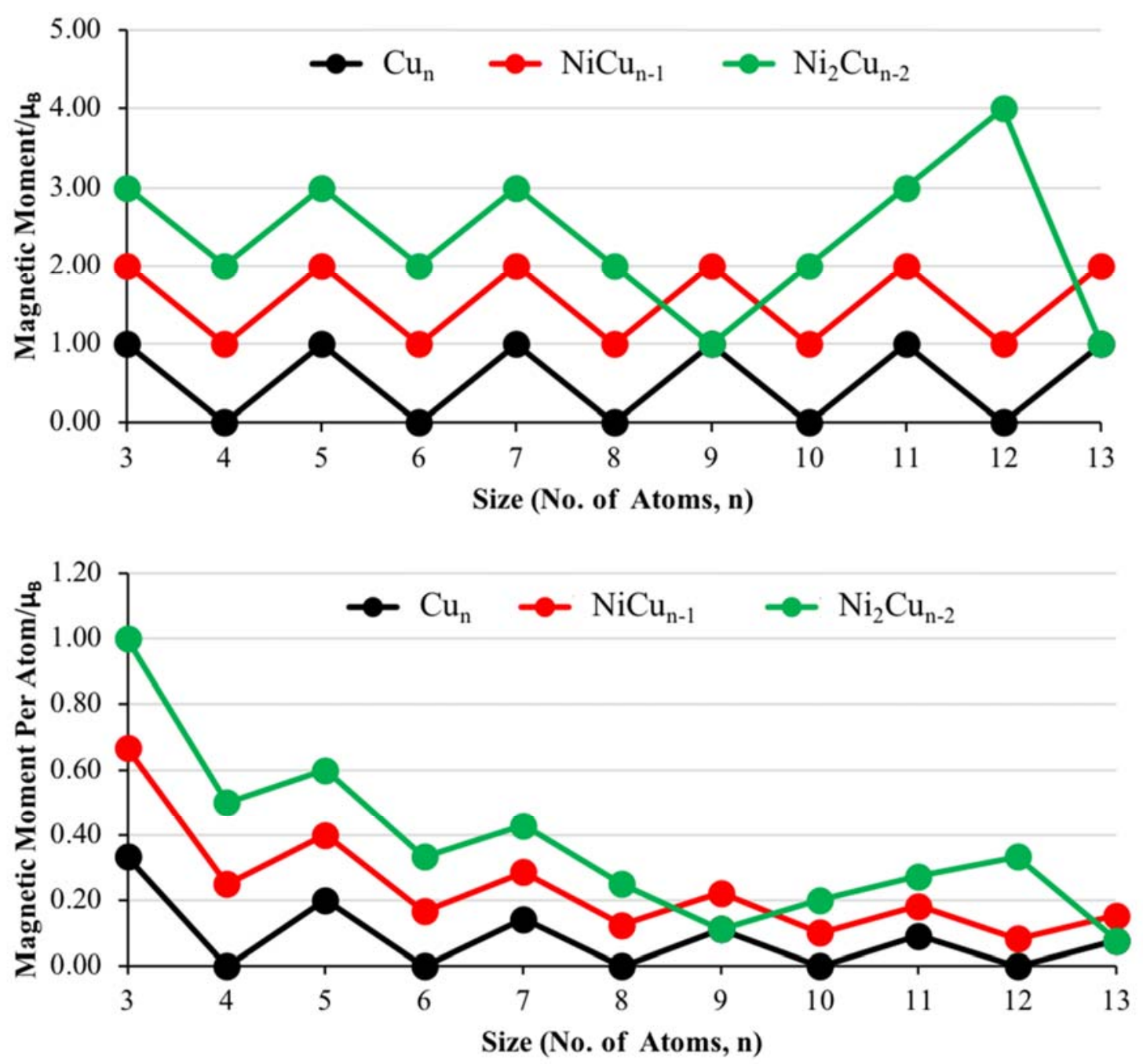

Figure 8. Size dependence of the total spin magnetic moment and the total spin magnetic moment per atom of the lowest energy structure for of the $\mathrm{Cu}_{n}, \mathrm{NiCu}_{n-1}$ and $\mathrm{Ni}_{2} \mathrm{Cu}_{n-2}(n=3-13)$ clusters. 


\section{Conclusion}

In this work, we have systematically investigated geometric structures, relative stabilities, electronic structures, reactivity descriptors and magnetic properties of the single and double $\mathrm{Ni}$ atoms doped into the ground-state structures of the $\mathrm{Cu}_{n}(n=3-13)$ clusters at the LCBLYP/LANL2DZ level.

Firstly, we searched the lowest energy structures of Ni doped copper clusters by doping one or two $\mathrm{Ni}$ atoms to the lowest energy structures of $\mathrm{Cu}_{n}$ with all possible atomic positions and possible spin multiplicities, followed by geometry optimizations. The most stable structures revealed that $\mathrm{Cu}-\mathrm{Cu}, \mathrm{Ni}-\mathrm{Cu}$ and $\mathrm{Ni}-\mathrm{Ni}$ bond lengths increase as the size of the clusters grows and approaches to the experimental bulk metal distance. The computed vibrational spectra were presented to identify the most stable structures.

In order to understand the relative stabilities of the clusters, the binding energy per atom, the fragmentation energies and the second-order energy differences were computed. It was found that $\mathrm{Ni}_{2}$-doped copper clusters and pure copper clusters have the highest and lowest binding energies per atom, respectively. These results signified that Ni-doped clusters can continue to gain an energy during the growth process. The positive fragmentation energies ensured that all the clusters are stable and $\mathrm{Cu}_{10}, \mathrm{NiCu}_{9}$ and $\mathrm{Ni}_{2} \mathrm{Cu}_{5}$ have the largest fragmentation energies in their corresponding classes of the clusters. The second-order energy differences indicated that the evennumbered clusters are more stable than the odd-numbered ones. All in all, the results showed that $\mathrm{Ni}_{2} \mathrm{Cu}_{11}$ cluster is the most stable one among $\mathrm{Cu}_{n}, \mathrm{NiCu}_{n-1}$ and $\mathrm{Ni}_{2} \mathrm{Cu}_{n-2}(n=3-13)$ clusters.

The HOMO-LUMO gap showed an oscillating behavior with the cluster size increasing. The substitution of $\mathrm{Cu}$ by $\mathrm{Ni}$ in the copper clusters enhances the chemical reactivity of large 
clusters and $\mathrm{Ni}_{2} \mathrm{Cu}_{10}$ is the most reactive one. On the basis of the calculated natural charges from the NBO calculation, it was noticed that charges are transferred from $\mathrm{Cu}$ to $\mathrm{Ni}$ atoms.

Next we investigated the electronic properties of the clusters, i.e., vertical ionization potential and vertical electron affinity. The VIPs calculated from HOMO energies give excellent agreement with the experimental values while the LUMO energy gives well correspondence with VEA values obtained from the energies of neutral and anionic clusters. These results revealed that HOMO and LUMO energies from LC-DFT calculations are reliable and can be used to predict the VIP and VEA of systems for which experimental results are not available.

The reactivity descriptors, such as chemical potential, chemical hardness and electrophilicity index, are useful tools to get insights to more complex systems involved in heterogeneous catalysis and in cluster's fragmentation reactions. $\mathrm{Ni}_{2} \mathrm{Cu}_{11}$ cluster has the lowest chemical potential while $\mathrm{Cu}_{13}, \mathrm{NiCu}_{12}$ and $\mathrm{Ni}_{2} \mathrm{Cu}_{10}$ clusters show the lowest chemical hardness in $\mathrm{Cu}_{n}, \mathrm{NiCu}_{n-1}$ and $\mathrm{Ni}_{2} \mathrm{Cu}_{n-2}$ clusters, respectively. Moreover, $\mathrm{Ni}_{2} \mathrm{Cu}_{10}$ and $\mathrm{Ni}_{2} \mathrm{Cu}_{6}$ clusters have the highest and the lowest electrophilicity index, respectively. The results show that Ni-doping into copper clusters affects the chemical potential, chemical hardness and electrophilic power of the pure copper clusters.

Moreover, we also found that the more stable cluster has the lesser static polarizability in average. For example, $\mathrm{Ni}_{2} \mathrm{Cu}_{11}$ cluster has the highest binding energies with the lowest static polarizability per atom, which is in agreement with MPP. This showed that the minimum polarizability principle is operative in the characterization of these clusters. We have also checked the minimum electrophilicity principle for $\mathrm{NiCu}_{2}$ isomers, and found that the more stable isomer has the smaller electrophilicity value. 
Finally, the total spin magnetic moment of $\mathrm{Cu}_{n}, \mathrm{NiCu}_{n-1}$ and $\mathrm{Ni}_{2} \mathrm{Cu}_{n-2}$ clusters have been computed and $\mathrm{Ni}_{2} \mathrm{Cu}_{10}$ cluster has the highest magnetic moment due to the lowest energy in quintet spin state. In general, the results indicated that the substitution of $\mathrm{Cu}$-atoms with $\mathrm{Ni}$-atoms in $\mathrm{Cu}_{n}$ clusters has conserved most of total spin magnetic moments. Based on these results, we conclude that long-range exchange interactions play a significant role in the study of metal clusters.

\section{Supporting Information}

The Supporting Information is available free of charge on the ACS Publications website at DOI: the optimized parameters, relative energies of the clusters in different spin states of the $\mathrm{Ni}_{m} \mathrm{Cu}_{n-m}(m=0-2 ; n=3-13)$ clusters etc.

\section{Acknowledgment}

The present work was partially supported by the MEXT program "Elements Strategy Initiative to Form Core Research Center", and the MEXT program "Priority Issue on Post-K computer" (Development of new fundamental technologies for high-efficiency energy creation, conversion/storage and use). T.I. and T.T. thank the financial support for JSPS KAKENHI Grant No. $17 \mathrm{~K} 14428$ and $16 \mathrm{KT} 0047$, respectively. A part of calculations was performed using the Research Center for Computational Science, Okazaki, Japan. 


\section{References}

(1) K. Philippot, P. Serp, Concepts in Nanocatalysis. In Nanomaterials in Catalysis; Wiley-VCH Verlag GmbH \& Co. KGaA, 2013; pp 1-54.

(2) A. T. Bell, G. C. Bond, D. T. Thompson, M. Valden, X. Lai, D. W. Goodman, T. Blasko, J. M. L. Nieto, K. Chen, A. T. Bell, E. Iglesia, T. Koyama, T. Komaya, P. L. Gai, M. Weyland, G. Durscher, N. D. Browning, S. J. Pennycook, F. Besenbacker, P. C. Thune, J. Loss, D. Wonter, P. J. Leustra, J. W. Niemantsverdriet, J. Corker, V. Vidal, A. Theolier, J. Thivolle-Cazat, J.-M. Basset, C. Nozkaki, C. G. Lugmair, A. T. Bell, T. D. Tilley, D. Kolb, K. P. De Jong, J. W. Geus, Science 2003, 299, 1688.

(3) J. R. Bhamore, S. Jha, A. K. Mungara, R. K. Singhal, D. Sonkeshariya, S. K. Kailasa, Biosens. Bioelectron. 2016, 80, 243.

(4) X. Jia, J. Li, L. Han, J. Ren, X. Yang, E. Wang, ACS Nano 2012, 6, 3311.

(5) H. Miao, D. Zhong, Z. Zhou, X. Yang, Nanoscale 2015, 7, 19066.

(6) P. Maity, S. Yamazoe, and T. Tsukuda, ACS Catal. 2013, 3, 182.

(7) Y. Nagai, K. Dohmae, Y. F. Nishimura, H. Kato, H. Hirata, N. Takahashi, Phys. Chem. Chem. Phys. 2013, 15, 8461 .

(8) S. Vukojević, O. Trapp, J.-D. Grunwaldt, C. Kiener, F. Schüth, Angew. Chem. Int. Ed. 2005, 44,7978 .

(9) Y. Zhu, Y. Zhu, X. Kong, X. Li, G. Ding, Y. W. Li, ACS Catal. 2014, 4, 3612.

(10) M. E. Sad, M. Neurock, E. Iglesia, J. Am. Chem. Soc. 2011, 133, 20384. 
(11) B. Bridier, M. A. G. Hevia, N. López, J. Pérez-Ramírez, J. Catal. 2011, 278, 167.

(12) C. W. Li, J. Ciston, M. W. Kanan, Nature 2014, 508, 504.

(13) K. Salorinne, X. Chen, R. W. Troff, M. Nissinen, H. Häkkinen, Nanoscale 2012, 4, 4095.

(14) N. Vilar-Vidal, J. Rivas, M. A. López-Quintela, Phys. Chem. Chem. Phys. 2014, 16, 26427.

(15) W. Yu, M. D. Porosoff, J. G. Chen, Chem. Rev. 2012, 112, 5780.

(16) R. Ferrando, J. Jellinek, R. L. Johnston, Chem. Rev. 2008, 108, 845.

(17) K. Jug, B. Zimmermann, P. Calaminici, A. M. Köster, J. Chem. Phys. 2002, 116, 4497.

(18) P. Jaque, A. Toro-Labbé, J. Chem. Phys. 2002, 117, 3208.

(19) S. Li, M. M. G. Alemany, J. R. Chelikowsky, J. Chem. Phys. 2006, 125, 34311.

(20) G. Guzmán-Ramírez, F. Aguilera-Granja, J. Robles, Eur. Phys. J. D 2010, 57, 49.

(21) G. H. Guvelioglu, P. Ma, X. He, R. C. Forrey, H. Cheng, Phys. Rev. Lett. 2005, 94, 26103.

(22) G. H. Guvelioglu, P. Ma, X. He, R. C. Forrey, H. Cheng, Phys. Rev. B 2006, 73, 155436.

(23) A. Poater, M. Duran, P. Jaque, A. Toro-Labbé, M. Solà, J. Phys. Chem. B 2006, 110, 6526.

(24) L. Padilla-Campos, J. Mol. Struct.(THEOCHEM) 2007, 815, 63.

(25) E. Fernández, M. Boronat, A. Corma, J. Phys. Chem. C 2015, 119, 19832.

(26) J. Barabás, T. Höltzl, J. Phys. Chem. A 2016, 120, 8862.

(27) B. R. Cuenya, Thin Solid Films 2010, 518, 3127.

(28) B. R. Cuenya, F. Behafarid, Surf. Sci. Rep. 2015, 70, 135. 
(29) L. R. Merte, M. Ahmadi, F. Behafarid, L. K. Ono, E. Lira, J. Matos, L. Li, J. C. Yang, B. R. Cuenya, ACS Catal. 2013, 3, 1460.

(30) R. Reske, H. Mistry, F. Behafarid, B. R. Cuenya, P. Strasser, J. Am. Chem. Soc. 2014, 136, 6978.

(31) Y. Xia, Y. Xiong, B. Lim, S. E. Skrabalak, Angew. Chem. Int. Ed. 2009, 48, 60.

(32) M. E. Tess, P. L. Hill, K. E. Torraca, M. E. Kerr, K. A. Abboud, L. McElwee-White, Inorg. Chem. 2000, 39, 3942.

(33) H. Bönnemann, R. Brinkmann, P. Britz, U. Endruschat, R. Mörtel, U. A. Paulus, G. J. Feldmeyer, T. J. Schmidt, H. A. Gasteiger, R. J. Behm, J. New Mater. Electrochem. Syst. 2000, 3, 199.

(34) M. Estrella, L. Barrio, G. Zhou, X. Wang, Q. Wang, W. Wen, J. C. Hanson, A. I. Frenkel, J. A. Rodriguez, J. Phys. Chem. C 2009, 113, 14411.

(35) J. Nerlov, I. Chorkendorff, Catal. Lett. 1998, 54, 171.

(36) J. Nerlov, I. Chorkendorff, J. Catal. 1999, 181, 271.

(37) J. Nerlov, I. Chorkendorff, Appl. Catal. A Gen. 2000, 191, 97.

(38) Y. Yang, M. G. White, P. Liu, J. Phys. Chem. C 2012, 116, 248.

(39) Y. Yang, J. Evans, J. A. Rodriguez, M. G. White, P. Liu, Phys. Chem. Chem. Phys. 2010, 12, 9909.

(40) N. Austin, B. Butina, G. Mpourmpakis, Prog. Nat. Sci. Mater. Int. 2016, 26, 487.

(41) P. A. Derosa, J. M. Seminario, P. B. Balbuena, J. Phys. Chem. A 2001, 105, 7917. 
(42) S. L. Han, X. Xue, X. C. Nie, H. Zhai, F. Wang, Q. Sun, Y. Jia, S. F. Li, Z. X. Guo, Phys. Lett. Sect. A Gen. At. Solid State Phys. 2010, 374, 4324.

(43) P. E. Blöchl, Phys. Rev. B 1994, 50, 17953.

(44) G. Kresse, D. Joubert, Phys. Rev. B 1999, 59, 1758.

(45) J. P. Perdew, K. Burke, M. Ernzerhof, Phys. Rev. Lett. 1996, 77, 3865.

(46) A. Seidl, A. Görling, P. Vogl, J. A. Majewski, M. Levy, Phys. Rev. B 1996, 53, 3764.

(47) H. Iikura, T. Tsuneda, T. Yanai, K. Hirao, J. Chem. Phys. 2001, 115, 3540.

(48) M. Kamiya, T. Tsuneda, K. Hirao, J. Chem. Phys. 2002, 117, 6010.

(49) T. Tsuneda, R. K. Singh, A. Nakata, J. Comput. Chem. 2016, 37, 1451.

(50) T. Tsuneda, R. K.Singh, A. Nakata, J. Comput. Chem. 2017, 38, 2020.

(51) M. Kamiya, H. Sekino, T. Tsuneda, K. Hirao, J. Chem. Phys. 2005, 122, 234111.

(52) R. K. Singh, T. Tsuneda, J. Comput. Chem. 2013, 34, 379.

(53) T. Tsuneda, R. K. Singh, J. Comput. Chem. 2014, 35, 1093.

(54) T. Tsuneda, S. Maeda, Y. Harabuchi, R. K. Singh, Computation 2016, 4, 23.

(55) J. W. Song, T. Hirosawa, T. Tsuneda, K. Hirao, J. Chem. Phys. 2007, 126, 154105.

(56) M. Couty, M. B. Hall, J. Comput. Chem. 1996, 17, 1359.

(57) C. Lee, W. Yang, R. G. Parr, Phys. Rev. B 1988, 37, 785.

(58) A. D. Becke, J. Chem. Phys. 1993, 98, 1372.

(59) A. D. Becke, Phys. Rev. A 1988, 38, 3098. 
(60) J. P. Perdew, Y. Wang, Phys. Rev. B 1992, 45, 13244.

(61) Y. Zhao, D. G. Truhlar, Theor. Chem. Acc. 2008, 120, 215.

(62) Gaussian 16, Revision A.03, M. J. Frisch, G. W. Trucks, H. B. Schlegel, G. E. Scuseria, M. A. Robb, J. R. Cheeseman, G. Scalmani, V. Barone, G. A. Petersson, H. Nakatsuji, X. Li, M. Caricato, A. V. Marenich, J. Bloino, B. G. Janesko, R. Gomperts, B. Mennucci, H. P. Hratchian, J. V. Ortiz, A. F. Izmaylov, J. L. Sonnenberg, D. Williams-Young, F. Ding, F. Lipparini, F. Egidi, J. Goings, B. Peng, A. Petrone, T. Henderson, D. Ranasinghe, V. G. Zakrzewski, J. Gao, N. Rega, G. Zheng, W. Liang, M. Hada, M. Ehara, K. Toyota, R. Fukuda, J. Hasegawa, M. Ishida, T. Nakajima, Y. Honda, O. Kitao, H. Nakai, T. Vreven, K. Throssell, J. A. Montgomery, Jr., J. E. Peralta, F. Ogliaro, M. J. Bearpark, J. J. Heyd, E. N. Brothers, K. N. Kudin, V. N. Staroverov, T. A. Keith, R. Kobayashi, J. Normand, K. Raghavachari, A. P. Rendell, J. C. Burant, S. S. Iyengar, J. Tomasi, M. Cossi, J. M. Millam, M. Klene, C. Adamo, R. Cammi, J. W. Ochterski, R. L. Martin, K. Morokuma, O. Farkas, J. B. Foresman, and D. J. Fox, Gaussian, Inc., Wallingford CT, 2016.

(63) M. Ernzerhof, J. Perdew, J. Chem. Phys. 1998, 109, 3313.

(64) J. P. Perdew, K. Burke, Y. Wang, Phys. Rev. B 1996, 54, 16533.

(65) J. P. Perdew, Electronic Structure of Solids '91; Ziesche, P.; Eschrig, H., Eds.; Akademie Verlag: Berlin, 1991.

(66) Z. Fu, G. W. Lemire, G. A. Bishea, M. D. Morse, J. Chem. Phys. 1989, 90, 3417.

(67) R. Pou-Amérigo, M. Merchán, I. Nebot-Gil, P. Å. Malmqvist, B. O. Roos, J. Chem. Phys. 1994, 101, 4893. 
(68) L. Lin, P. Claes, P. Gruene, G. Meijer, A. Fielicke, M. T. Nguyen, P. Lievens, ChemPhysChem 2010, 11, 1932.

(69) A. E. Reed, L. A. Curtiss, F. Weinhold, Chem. Rev. 1988, 88, 899.

(70) J. F. Janak, Phys. Rev. B 1978, 18, 7165.

(71) W. Yang, Y. Zhang, P. Ayers, Phys. Rev. Lett. 2000, 84, 5172.

(72) M. B. Knickelbein, Chem. Phys. Lett. 1992, 192, 129.

(73) O. Ingólfsson, U. Busolt, K. Sugawara, J. Chem. Phys. 2000, 112, 4613.

(74) P. K. Chattaraj, U. Sarkar, D. R. Roy, Chem. Rev. 2006, 106, 2065.

(75) R. G. Parr, W.Yang, Density Functional Theory of Atoms and Molecules; Oxford University Press: Oxford, U.K., 1989.

(76) T. A. Koopmans, Physica 1933, 1, 104.

(77) S. Noorizadeh, Chin. J. Chem. 2007, 25, 1439.

(78) S. Noorizadeh, J. Phys. Org. Chem. 2007, 25, 514.

(79) P. K. Chattaraj, Ind. J. Phys. 2007, 81, 871. 


\section{Table of Contents (TOC) Image}

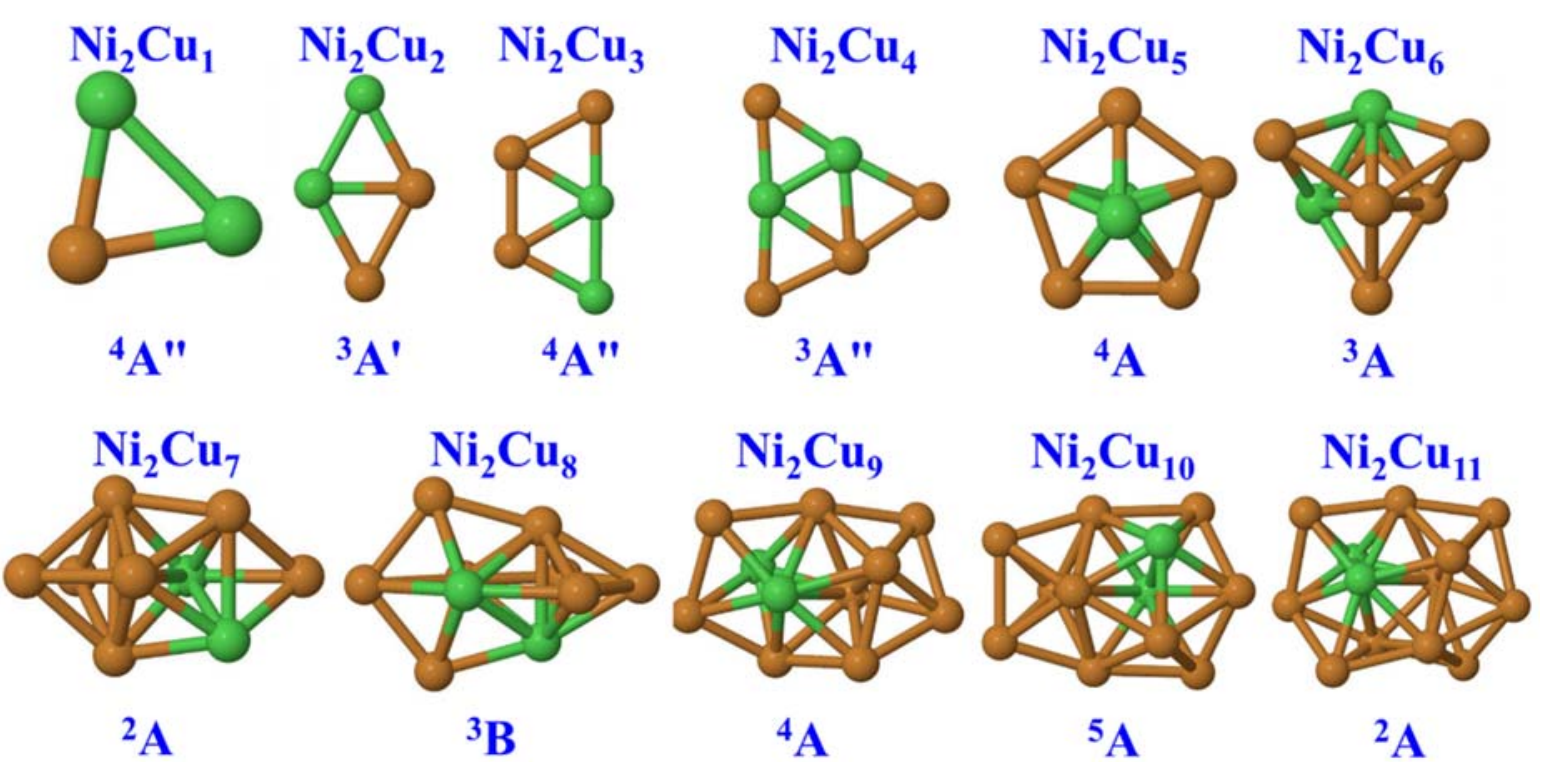

A systematic investigation of the lowest energy structures of $\mathrm{Ni}$ doped copper clusters are performed by doping one or two $\mathrm{Ni}$ atoms to the lowest energy structures of $\mathrm{Cu}_{n}$ with all possible atomic positions and possible spin multiplicities. In LC-DFT computations, the vertical ionization potentials calculated from HOMO energies give excellent agreement with the experimental values. It is shown that the substitution of $\mathrm{Cu}$ by $\mathrm{Ni}$ in the copper clusters enhances the chemical reactivity of large clusters. 